\title{
Unenlagiinae revisited: dromaeosaurid theropods from South America
}

\author{
FEDERICO A. GIANECHINI and SEBASTIÁN APESTEGUÍA \\ CONICET - Área de Paleontología, Fundación de Historia Natural 'Félix de Azara' \\ Departamento de Ciencias Naturales y Antropología \\ CEBBAD, Universidad Maimónides, Hidalgo 775 (1405BDB), Ciudad Autónoma de Buenos Aires, Argentina \\ Manuscript received on October 30, 2009; accepted for publication on June 21, 2010
}

\begin{abstract}
Over the past two decades, the record of South American unenlagiine dromaeosaurids was substantially increased both in quantity as well as in quality of specimens. Here is presented a summary review of the South American record for these theropods. Unenlagia comahuensis, Unenlagia paynemili, and Neuquenraptor argentinus come from the Portezuelo Formation, the former genus being the most complete and with putative avian features. Neuquenraptor is more incomplete and exhibits pedal features resembling those of Unenlagia. The earliest and most complete South American dromaeosaurid is Buitreraptor gonzalezorum, whose preserved cranial remains, provides important data in the characterization of unenlagiines. The most recently described, Austroraptor cabazai, also with cranial remains, allows further comparisons with Laurasian lineages and a better characterization of unenlagiines. The possible synonymy between Unenlagia and Neuquenraptor is discussed. Additional evidences from Brazil and Colombia show that dinosaurs with similar dentition to that of unenlagiines were present in the whole South America. However, it is not possible to discart that these remains may belong to other unknown maniraptoran lineages, considering the increasing number of taxa of this group found in South America.
\end{abstract}

Key words: Deinonychosauria, Dromaeosauridae, South America, Unenlagiinae.

\section{INTRODUCTION}

The Dromaeosauridae is a family of highly derived small to mid-sized theropod dinosaurs characterized by the presence of a raptorial second pedal digit and a tail stiffened by the elongated prezygapophyses and chevrons of the medial to distal posterior vertebrae. The manus and pes of these theropods bear sharp trenchant claws and the pubis is generally posteriorly oriented. The majority of phylogenetic analyses found this group of theropods as the closest relatives to Avialae.

After the discovery of Dromaeosaurus albertensis in Canada (Matthew and Brown 1922) and Velociraptor mongoliensis in Mongolia (Osborn 1924) during the first decades of the twentieth century, and the descrip-

Proceedings of the Third Gondwanan Dinosaur Symposium Correspondence to: Federico A. Gianechini

E-mail: smilodon.80@gmail.com tion of Deinonychus antirrhopus from the USA (Ostrom 1969), many other new dromaeosaurids have been found in the northern continents, mainly in North America and Asia. The finding of many quite complete specimens with an outstanding preservation in the USA, Canada, Mongolia, and in the last decades in China, prompted a great advance in the knowledge of these theropods. This record suggested that the greatest diversity and distribution of dromaeosaurids was circumscribed to the Laurasian continents.

However, in the beginning of the 1990s new dromaeosaurid species were discovered in South America, mainly from the Cretaceous beds of Argentina, which showed characters that resemble not only those present in dromaeosaurids, but also some others considered as proper avian. The first Argentine theropod considered as a dromaeosaurid was Unenlagia comahuensis No- 
vas and Puerta 1997, which shares some features with avians mainly in the scapula and pelvis (Novas and Puerta 1997, Novas 2004). Later, more remains were found in other Argentine localities. New material very similar to that of Unenlagia comahuensis was attributed to a new species of the same genus, Unenlagia paynemili Calvo et al. 2004. In 2005, a new and more fragmentary specimen was described, mainly preserving few remains of the hind limbs. It was assigned to a new genus and species, Neuquenraptor argentinus Novas and Pol 2005. In the same year, the earliest and most complete South American dromaeosaurid to date, Buitreraptor gonzalezorum (Makovicky et al. 2005), was described. The available skeletons of this species provide excellent information for a better comprehension of the southern dromaeosaurid anatomy. The most recently described South American dromaeosaurid was Austroraptor cabazai Novas et al. 2009, which bears some unusual characters not observed in Laurasian dromaeosaurids and is therefore important in the characterization of this group of southern theropods. This same group also has a representative in Madagascar, Rahonavis ostromi (Forster et al. 1998), previously considered an avialan but lately linked with Unenlagia mainly through pelvic characters (Novas 2004).

Many phylogenetic analyses found these South American dromaeosaurids in a monophyletic clade named Unenlagiinae (Bonaparte 1999, Makovicky et al. 2005). The anatomical differentiation of this group of South American theropods with respect to Laurasian dromaeosaurids could have been due to a vicariant evolution produced after the separation of Pangea into Laurasia and Gondwana during the Late Jurassic (Makovicky et al. 2005, Novas and Pol 2005). This separation would have resulted in the isolation of the South American dromaeosaurids, allowing a parallel evolution with respect to those of Laurasia and, thus, creating a new South American lineage itself.

A brief overview of the South American dromaeosaurids and other possible deinonychosaurian taxa is presented here. Since Cretaceous Argentinean fossil record of unenlagiines is the most complete and diverse of South America, the most important features of individual taxa are here characterized according to stratigraphic order, providing some comments and reinterpretations of certain materials and discussions on the ideas previously exposed by other autors.

\section{InSTITUTIONAL ABBREVIATIONS}

AMNH - American Museum of Natural History, New York, USA.

IGM - Mongolian Institute of Geology, Ulan Baatar, Mongolia.

IVPP - Institute of Vertebrate Paleontology and Paleoanthropology, Beijing, China.

MCF PVPH - Museo Municipal Carmen Funes, Plaza Huincul, Neuquén, Argentina.

MCZ - Museum of Comparative Zoology, Cambridge, Massachussets, USA.

MML - Museo Municipal de Lamarque, Río Negro, Argentina.

MPCA - Museo Carlos Ameghino, Cipolletti, Río Negro, Argentina.

MUCPv - Museo de Geología y Paleontología de la Universidad Nacional del Comahue, Neuquén, Argentina.

UCMP - University of California Museum of Paleontology, Berkeley, CA, USA.

DROMAEOSAURID THEROPODS FROM ARGENTINA

THEROPODA Marsh, 1881

MANIRAPTORA Gauthier, 1986

DEINONYCHOSAURIA Colbert and Russel, 1969

Dromaeos AURIDAE Matthew and Brown, 1922 UNENLAGIINAE Bonaparte, 1999

\section{Buitreraptor gonzalezorum}

Makovicky, Apesteguía and Agnolín, 2005

Materials: The holotype (MPCA 245) (Figs. 1B, 2B) consists of an almost complete adult skeleton, including a partial articulated skull with both incomplete maxillae with teeth in situ, left jugal, both postorbitals, both quadrates, right squamosal, both incomplete nasals, both frontals, both parietals, the occipital condyle, and mandibular bones, including both dentaries with in situ teeth, both splenials, left angular, and left surangular. The postcranium includes cervical, dorsal, sacral, and caudal vertebrae, cervical and dorsal ribs, chevrons, both scapulocoracoids, furcula, both ilia, right ischium, both humeri, right radius and ulna, metacarpals and manual phalanges, both femora, right tibia and fibula, left in- 


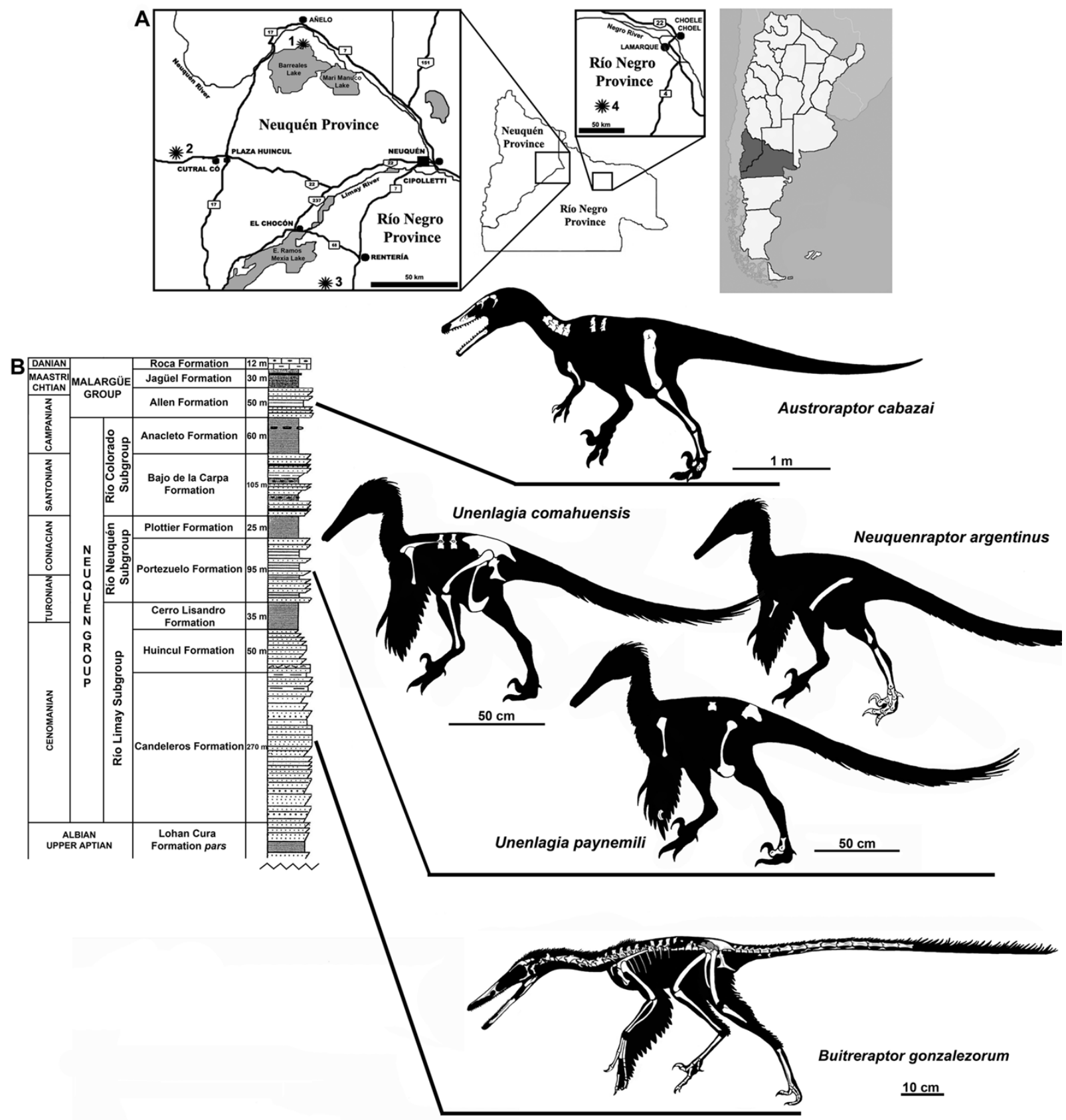

Fig. 1 - A: geographic provenance of the Patagonian dromaeosaurids taxa. The numbers in the maps correspond to the localities of provenance of each taxon. 1: Futalongko Site, Lago Barreales Paleontological Center, Neuquén Province: Unenlagia paynemili. 2: Sierra del Portezuelo, Neuquén Province: Unenlagia comahuensis and Neuquenraptor argentinus. 3: La Buitrera, Río Negro Province: Buitreraptor gonzalezorum. 4: Bajo de Santa Rosa, Río Negro Province: Austroraptor cabazai. B: stratigraphic provenance of Patagonian dromaeosaurid taxa. Each taxon is figured schematically through its body silhouette containing the preserved bones (Buitreraptor modified from Jaime Headden 2008). 
complete tibia and fibula, metatarsals, several pedal phalanges, and indetermined fragments of bone. The holotype of Buitreraptor was found in complete articulation in the field, indicating null or little transporting from the site of death.

A referred specimen (MPCA 238) consists of an almost complete right ilium and pubis, right hindlimb (femur, tibia, astragalus, metatarsals, and phalanges), and sacrum, all preserved in articulation.

Locality and horizon: Both the holotype and referred specimen were found at the fossiliferous locality of 'La Buitrera', located in the northwestern Río Negro Province, Patagonia, Argentina, close to the southern shore of the Ezequiel Ramos-Mexía Lake (Fig. 1). Its sedimentary beds correspond to the Candeleros Formation (Cenomanian) and show a high diversity of taxa with a superb preservation of the fossils, which make this fossiliferous locality one of the most outstanding and important of Gondwana. The 'La Buitrera' locality presents a peculiar bias towards micro and mesovertebrates, including remains of sphenodontids, crocodyliforms, basal limbed snakes, and mammals (including dryolestoids) (Carignano et al. 2002, Apesteguía and Novas 2003, Pol and Apesteguía 2005, Apesteguía and Zaher 2006). Nevertheless, dinosaurs are also present, including carcharodontosaurid and noasaurid theropods, and rebbachisaurid and basal titanosaur sauropods (Calvo and Salgado 1995, Coria and Salgado 1995, Gallina and Apesteguía 2005, Brissón Egli and Apesteguía 2008).

Main anatomical features and comments: Buitreraptor is the earliest dromaeosaurid discovered in South America to date and the most complete one (Makovicky et al. 2005). It bears some anatomical features, mainly cranial and dental ones, which distinguish it from Laurasian dromaeosaurid lineages. The skull is elongated and low (Fig. 2B, a, b), exceeding the femoral length by 25\% (Makovicky et al. 2005; synapomorphy of Unenlagiinae sensu Novas et al. 2009). All the preorbital bones are very long. Both maxillae are preserved only at mid-length and bear a large maxillary fenestra. This fenestra is oval in shape, with its major diameter in anteroposterior direction, instead of being small, oval, teardropshaped, and dorsally displaced (Fig. 2B, a) as in most dromaeosaurids (e.g. Colbert and Russel 1969, Ostrom 1969, Sues 1977, Currie 1995, Barsbold and Osmólska 1999, Burnham et al. 2000, Xu and Wu 2001, Burnham 2004, Norell et al. 2006, Turner et al. 2007, X. Xu, unpublished data). A maxillary fenestra enlarged and not dorsally displaced is proposed as a synapomorphy of Unenlagiinae by Novas et al. (2009). Posterior to the maxillary fenestra is the antorbital fenestra (inner antorbital fenestra sensu Witmer 1997), which remains separated by a narrow interfenestral bar (Fig. 2B, a) (Makovicky et al. 2005). The nasals are very long, flat, and narrow (Fig. 2B, b), suggesting an elongated and narrow snout, as in Velociraptor and Tsaagan (Makovicky et al. 2005, Norell et al. 2006), as well as in some troodontids like Byronosaurus jaffei (Makovicky et al. 2003). The frontals are also elongated, with laterally projected postorbital rami, resembling other dromaeosaurids. The jugal is low and the postorbital has the triangular trirradiate form that is common among dromaeosaurids. The quadrate has an enlarged quadrate foramen (Fig. 2B, c), thus differing from the general condition observed in dromaeosaurids. However, the condition of Buitreraptor resembles that of troodontids, in which this character is better represented, as seen in Troodon formosus and Sinovenator changii, (Varrichio 1997, X. Xu, unpublished data).

The dentary is very long and low, with dorsal and ventral parallel rims that run horizontally along the entire length. On the lateral side, close to the alveolar margin, there is a deep subalveolar groove that lodges a row of nutrient foramina (Fig. 2B, a), as is frequent in troodontids (Makovicky et al. 2003, 2005). Among the postdentarial bones, only the splenials, left angular, and left surangular are present. The splenials are articulated with the medial side of the dentary, but they are not very visible because the jaws are in occlusion and still partially covered by matrix.

The teeth of Buitreraptor are very characteristic mainly because of their high number and diminutive size regarding the dimensions of the skull, the absence of denticles on both mesial and distal margins, the presence of longitudinal grooves, a strong lateral compression of the crown, eight-shaped basal section, and an absence of any constriction in the root-crown transition (Makovicky et al. 2005, Gianechini et al. 2009). This 
suite of dental characters is only observed in Buitreraptor and can be considered as potentially autapomorphic of this species (Gianechini et al. 2009). In most Laurasian dromaeosaurids the teeth are larger than in Buitreraptor (e.g. Colbert and Russel 1969, Ostrom 1969, Sues 1977, Currie 1995, Xu and Wu 2001, Currie and Varricchio 2004), and they are fewer in number, since most dromaeosaurids bear 11 to 16 dentary teeth (Norell and Makovicky 2004), whereas Buitreraptor bears up to 20 alveoli (this estimate take into account that many alveoli are not preserved and broken, but due to the length of the dentary, the extension of the dental row and the size of the alveoli, it is estimated that more than 20 alveoli were present in the jaw). Among deinonychosaurs, only troodontids have such large dental count (Makovicky et al. 2003, Makovicky and Norell 2004). The complete absence of denticles is not a common character among dromaeosaurids. However, some taxa possess a wide variety of denticle development, ranging from total absence in one border (generally the mesial) to the total absence, like in Microraptor, Bambiraptor, Shanag, and Sinornithosaurus (Burnham et al. 2000, Xu et al. 2000, Hwang et al. 2002, Burnham 2004, Hwang 2005, Turner et al. 2007, X. Xu, unpublished data). Nevertheless, the total absence of denticles in some of these taxa is not characteristic of all teeth, as is conversely observed in Buitreraptor (Gianechini et al. 2009), Austroraptor (Novas et al. 2009) and avialans, as will be discussed later. The presence of grooves on the sides of the crown is strange among dromaeosaurids. Moreover, the grooves observed in the teeth of Sinornithosaurus (Xu and Wu 2001, X. Xu, unpublished data) and some isolated teeth assigned with doubts to Dromaeosaurus (Sankey et al. 2002) are very different from those of Buitreraptor, both in morphology, density, and location. Accordingly, the eight-shaped basal section is not common among dromaeosaurid teeth, and only is recorded in some taxa such as Saurornitholestes (Currie et al. 1990, Sankey et al. 2002), Tsaagan (Norell et al. 2006), and Pyroraptor (Allain and Taquet 2000, S. Apesteguía, personal observation). Nevertheless, the teeth of these taxa are not as labiolingually compressed as those of Buitreraptor.

The cervical vertebrae (Fig. 2B, d) have low neural spines and small epipophyses, in contrast to the large epipophyses observed on the cervical vertebrae of Deinonychus and Velociraptor (Ostrom 1969, Norell et al. 2006). Carotid processes are present in the posterior cervical centra as in some dromaeosaurids, such as Microraptor and Tsaagan, and also in troodontids and alvarezsaurids (Hwang et al. 2002, Makovicky and Norell 2004, Norell et al. 2006). A characteristic feature of Buitreraptor is the presence of low ridges on the ventrolateral corners of the last cervical centrum, which terminate posteriorly as small tubers (Makovicky et al. 2005). The dorsal vertebrae (Fig. 2B, e) have tall and rectangular neural spines, as is common among dromaeosaurids, without a distal transverse expansion as a spine table. Hypapophyses are present on the ventral side of the anterior dorsal centrae, as in the dromaeosaurids Velociraptor, Saurornitholestes, Deinonychus, Luanchanraptor, Bambiraptor, Sinornithosaurus, Microraptor, and Rahonavis (Ostrom 1969, Forster et al. 1998, Norell and Makovicky 1999, Burnham 2004, Lü et al. 2007, X. Xu, unpublished data), and also in troodontids, oviraptorosaurs, alvarezsaurids, ornithomimosaurs, Ornitholestes hermanni, and basal avialans such as hesperornithiforms and Ichthyornis (Osmólska et al. 1972, Kurzanov 1981, Perle et al. 1994, Norell and Makovicky 1999, Barsbold et al. 2000, Norell et al. 2000, Currie and Dong 2001, Makovicky et al. 2003, Clarke 2004). The dorsal vertebrae of Buitreraptor bear stalked parapophyses, considered as a common feature among Dromaeosauridae, despite also being observed in alvarezsaurids (Novas 1997, Norell and Makovicky 1999) and in the basal bird Confuciusornis sanctus (Chiappe et al. 1999). The caudal vertebrae (Fig. 2B, f) are low and elongated as in other dromaeosaurids, and the distal ones are devoid of neural spines. Unlike Laurasian lineages, the prezygapophyses of these vertebrae are not anteriorly extended forming bony rods, and they only overlap up to half of the preceding vertebra (Makovicky et al. 2005). Some chevrons are present, which are dorsoventrally compressed and bifids at their anterior and posterior ends, as in other paravians (Makovicky et al. 2005).

The pectoral girdle of Buitreraptor is represented by the scapulocoracoid and furcula. No evidence of sternum is available, thus is not possible to know whether this element was present. The furcula (Fig. 


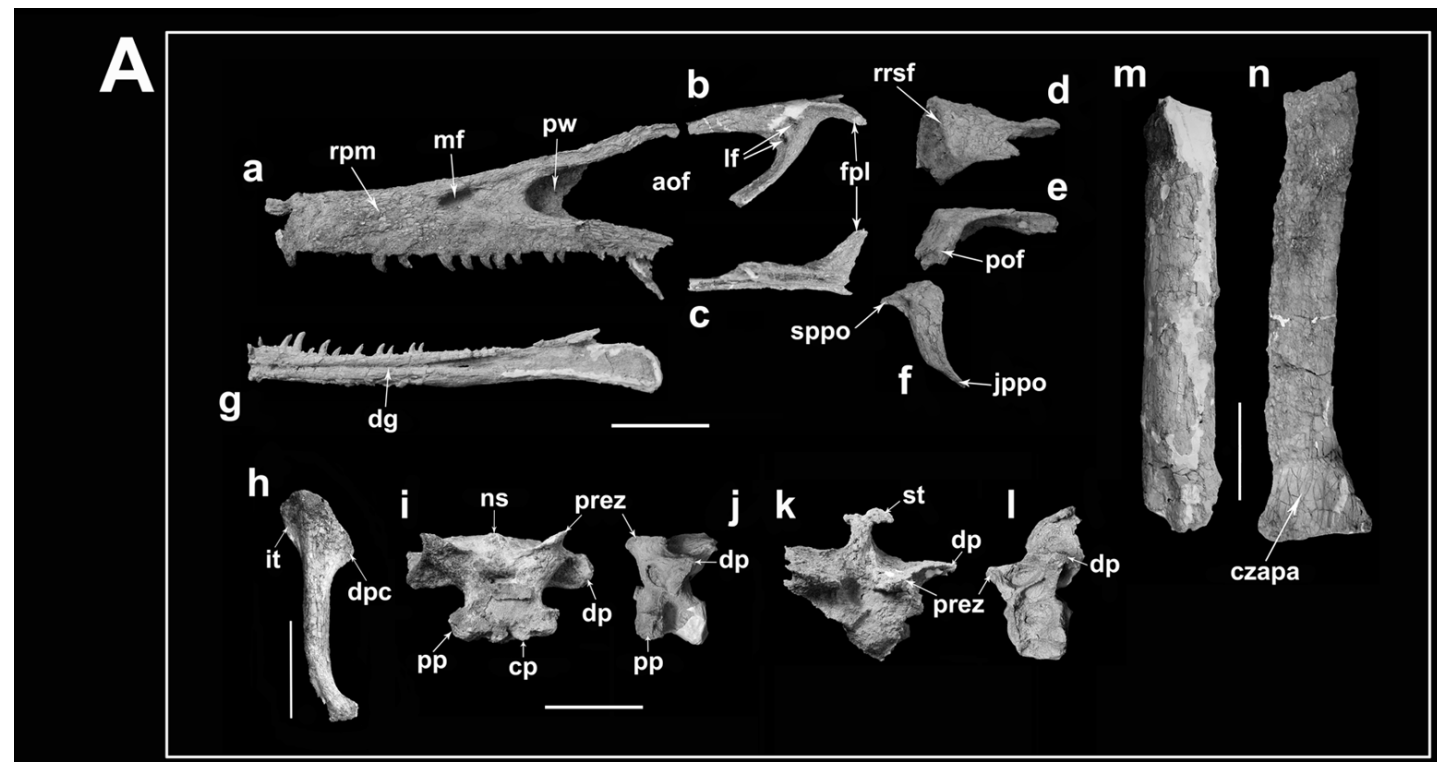

B
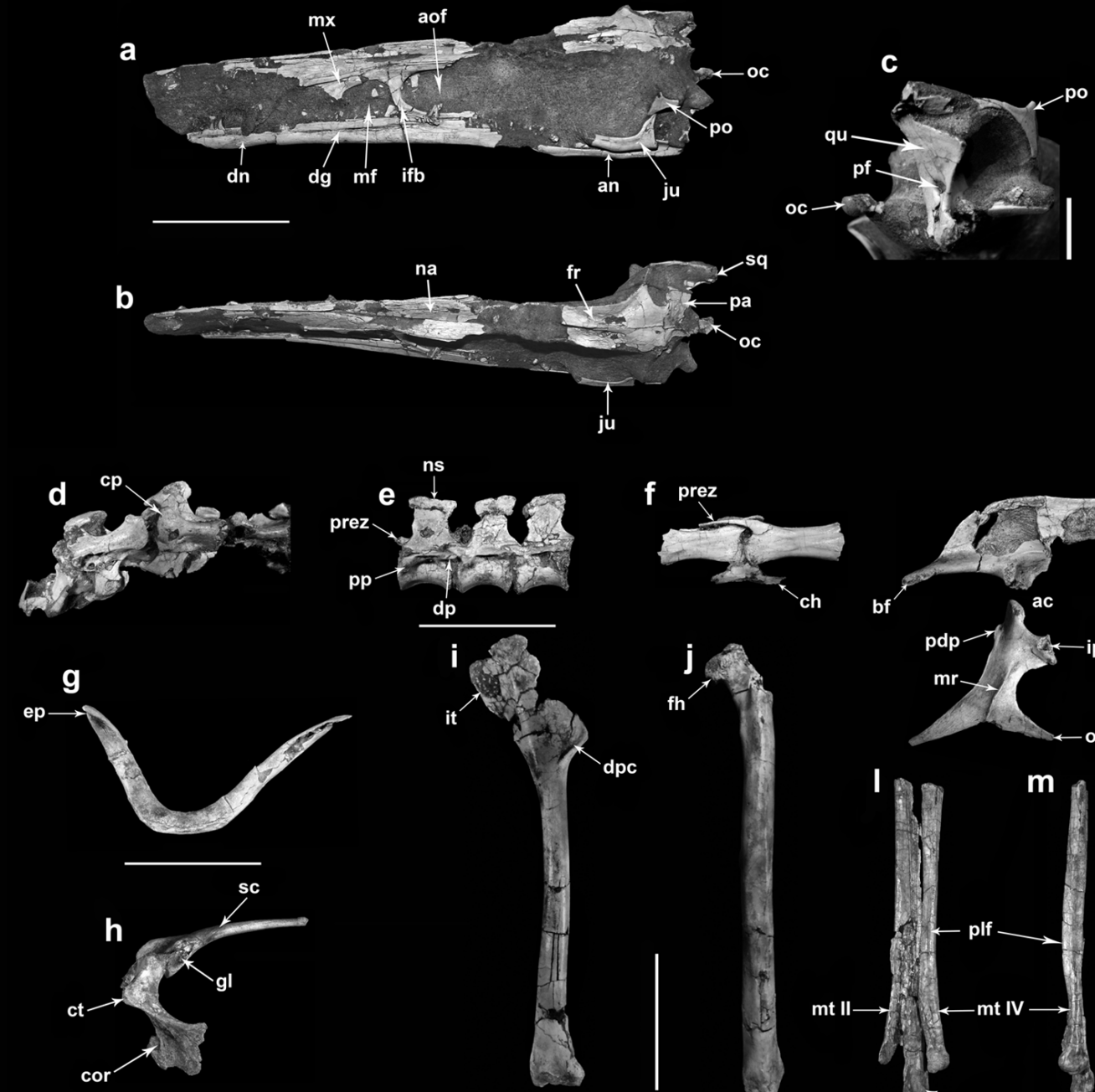

f prez
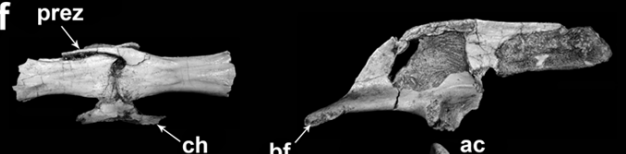

bf
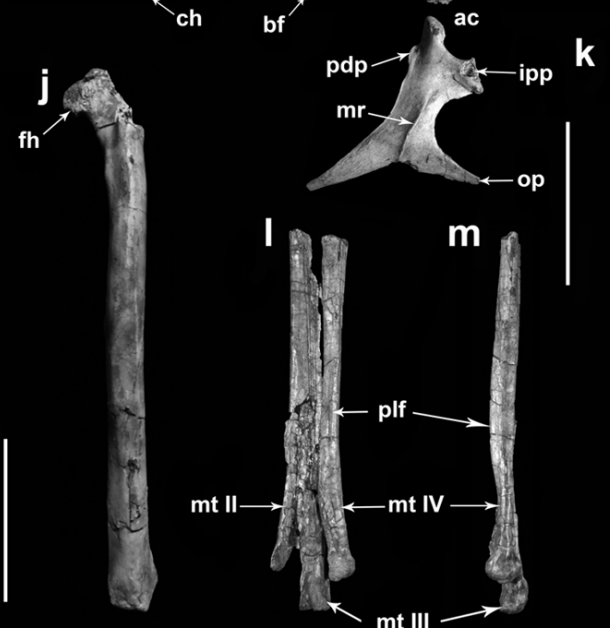

An Acad Bras Cienc (2011) 83 (1) 
Fig. 2 - A: holotype of Austroraptor cabazai (MML-195); a-g: skull bones; a: left maxilla; b and c: left lacrimal, in lateral and ventral views; d and e: right frontal, in dorsal and lateral views; f: right postorbital, in lateral view; g: left dentary, in lateral view; h: right humerus, in lateral view; i-l: presacral vertebrae; i and j: cervical 8th?, in cranial and left lateral views; $k$ and 1 : dorsal 4th?, in cranial and left lateral views; m: left femur, in lateral view; n: right tibia, in cranial view. Scale bars: $5 \mathrm{~cm}$. B: Buitreraptor gonzalezorum; a-k: holotype (MPCA 245); a and b: skull, in left lateral and dorsal views; c: close-up of the right quadrate; $\mathrm{d}$ : cervicodorsal vertebrae, in ventral view; e and f: mid-dorsal and distal posterior vertebrae, in lateral view; g: furcula, in posterior view; h: scapulocoracoid, in lateral view; i: right humerus, in lateral view; $\mathrm{j}$ : left femur, in anterior view; k: right ilium and ischium, in lateral view; 1-m: referred material (MPCA 238); 1 and m: right metatarsus, in plantar and lateral view. Scale bars: $5 \mathrm{~cm}$, except in c $(1 \mathrm{~cm})$. Abbreviations: ac, acetabulum; an, angular; aof, antorbital fenestra; bf, brevis fossa; cor, coracoid; cp, carotid process; ct, coracoid tubercle; czapa, contact zone of the ascendent process of the astragalus; dg, dentary groove; dn, dentary; dp, diapophysis; dpc, deltopectoral crest; ep, epicleidum; fh, femur head; fpl, fan-shaped process of the lacrimal; fr, frontal; gl, glenoid; ifb, interfenestral bar; ipp, pubic process of the ischium; it, internal tuberosity; jppo, jugal process of the postorbital; ju, jugal; lf, lacrimal foramina; mf, maxillar fenestra; mr, medial ridge; mt II, III, IV, metatarsals II, III and IV; mx, maxilla; na, nasal; ns, neural spine; oc, occipital condyle; op, obturator process; pa, parietal; pdp, proximodorsal process; pf, pneumatic foramen; plf, posterolateral flange of metatarsal IV; po, postorbital; pof, postorbital process of the frontal; pp, parapophysis; prez, prezygapophysis; pw: postantral wall; qu, quadrate; rpm, anterior process of the maxilla; rrsf, anterior rim of the supratemporal fenestra; sc, scapula; sppo, squamosal process of the postorbital; sq, squamosal; st, spinal table.

$2 \mathrm{~B}, \mathrm{~g}$ ) is stout, curved, with a very rudimentary hypocleidum, and is nearly U-shaped in form. Moreover, the furcula of Buitreraptor is pneumatic, being hollow and reinforced by internal trabeculae (Makovicky et al. 2005). The strap-like scapular blade (Fig. 2B, h) is curved close to the glenoid, with a triangular acromion that resembles that of other dromaeosaurids such as Sinornithosaurus and Velociraptor, as well as that of Archaeopteryx (Ostrom 1976b, Norell and Makovicky 1999, Xu et al. 1999, X. Xu, unpublished data). The coracoid (Fig. 2B, h) is bent in an approximately straight angle between the glenoid portion and the ventral region, the latter being expanded as a blade-like structure. The anterior surface of the coracoid has a prominent tubercle ("biceps tubercle" or "biceps tuber" for Ostrom 1974, Xu et al. 1999, Burnham 2004, Makovicky et al. 2005, and other authors) at the point of flexion of the coracoid. The glenoid appears to be laterally directed, as in Archaeopteryx (Ostrom 1976b, Wellnhofer 1992, Paul 2002). In many dromaeosaurids the coracoid acquires a L-shape, reaching the dorsal part that articulates with the scapula at a $90^{\circ}$ angle with respect to the ventral part, as in Buitreraptor. This flexion allows the ventral portion of the coracoid to articulate with the anterolateral margin of the sternum, as occurs in Bambiraptor (Burnham et al. 2000, Burnham 2004), and brings the glenoid into a lateral position. In this way, the general form of the scapulocoracoid is reminiscent of that of Asian dromaeosaurids, such as Microraptor and Sinornithosaurus, and also of that of basal birds including Archaeopteryx and Confuciusornis (Ostrom 1975, 1976a, b, 1986, Wellnhofer 1992, 1993, Chiappe et al. 1999, Norell and Makovicky 1999, Xu et al. 1999, 2000, Hwang et al. 2002, X. Xu, unpublished data).

The forelimb of Buitreraptor is proportionally very long, as in Sinornithosaurus and Microraptor (Xu et al. 1999, 2000, X. Xu, unpublished data). The humerus (Fig. 2B, i) has a well-developed deltopectoral crest, similar in form to that of Unenlagia comahuensis (Novas and Puerta 1997), sharing an internal tuberosity with a straight edge (Makovicky et al. 2005). The shaft is long and slender, slightly posteriorly bowed, and distally expanded into radial and ulnar condyles, which are separated by a shallow groove. The ulna and radius are both articulated and subequal in length, but the radial shaft has a smaller diameter. The ulnar shaft is posteriorly bowed, and the proximal articular end is subtriangular in proximal view, with the olecranon process located on its proximoventral margin. Accordingly, the general aspect of the ulna is very similar to other maniraptorans (e.g. Ostrom 1969, Norell and Makovicky 1999, Hwang et al. 2002, Burnham 2004, X. Xu, unpublished data). Three metacarpals are partially preserved, including metacarpal I, which is shorter than the others. 
The pelvis shares several features with other dromaeosaurids, such as Sinornithosaurus, Microraptor, and Rahonavis, but also with early birds as Archaeopteryx (Ostrom 1976b, Wellnhofer 1992, 1993, Forster et al. 1998, Xu et al. 1999, Xu et al. 2000, Hwang et al. 2002, $\mathrm{X}$. Xu, unpublished data). The ilium (Fig. 2B, k) shows a slightly convex dorsal rim, with a posteriorly curved postacetabular blade bearing a posterior concave rim due to the posterior expansion of the brevis shelf (character 227, Turner et al. 2007), resembling other unenlagiines (an issue that will be discussed later). A peculiar feature is a strong lateral torsion of the dorsal rim of the iliac blade at the level of the ischiadic peduncle, so that dorsal margins of both iliac blades diverge later from the sagittal axis at this zone. A similar eversion of the dorsal margin of the iliac blade is also observed in Sinovenator (Xu et al. 2002, X. Xu, unpublished data), whereas in Velociraptor and Archaeopteryx the dorsal margin of the ilium, above the ischiac process, is thickened and slightly laterally everted, and the blade is laterally concave (Wellnhofer 1974, Norell and Makovicky 1997), thus resembling the ilium of Buitreraptor.

The acetabulum is medially partially occluded, a derived avian feature also present in Unenlagia comahuensis (Novas and Puerta 1997). A supracetabular crest is present, similar to that of Rahonavis (Forster et al. 1998), and the brevis shelf is laterally projected and posteriorly extended beyond the posterior end of the vertical lamina (Makovicky et al. 2005). However, in the referred material, the brevis shelf is slightly more laterally projected and more ventrally curved at the posterior end, so some small differences can be observed between the two specimens, which seem to be a case of intraspecific variation. The pubis is preserved in the referred material, and is vertically oriented with a posteriorly curved distal half. Unfortunately the distalmost portion of the pubis is not preserved, and therefore it is not possible to observe the form and degree of fusion at the symphysis. The ischium (Fig. 2B, k) is platelike, as in other paravians, with an anteroposteriorly short iliac process and an anteriorly projected ischiadic process, which is dorsoventrally expanded. The ischium tapers distally to a posteroventrally oriented pointed end. The obturator process is long, pointed, and anteroventrally projected, as in Microraptor, Sinornithosaurus, and Rahonavis (Forster et al. 1998, Hwang et al. 2002, $\mathrm{X}$. Xu, unpublished data). A posterodorsal process is present, similar to the proximodorsal process of Bambiraptor, Sinornithosaurus, Microraptor, and Rahonavis among dromaeosaurids, the one of the troodontid Sinovenator, and of early birds such as Archaeopteryx, Enantiornithes, Iberomesornis, and Confuciusornis (Ostrom 1976b, Forster et al. 1998, Chiappe et al. 1999, Xu et al. 1999, 2000, Burnham et al. 2000, Hwang et al. 2002, Burnham 2004, X. Xu, unpublished data). On the lateral side, a sharp ridge is extended in dorsoventral direction, approximately at the middle of the shaft, dividing the latter into anterior and posterior halves.

The femur (Fig. 2B, j) is a slender bone, 25\% shorter than the skull, with a ventrolaterally oriented head, and without a distinct neck (Makovicky et al. 2005). The shaft is strongly anteriorly bowed, as in some non-avian theropods and avialans (Ostrom 1976b, Norell and Makovicky 1999, X. Xu, unpublished data). The fourth trochanter is poorly developed, as common among dromaeosaurids, and a conspicuous lateral ridge (linea intermuscularis lateralis sensu Hutchinson 2001) is present, which extends from the base of the posterior trochanter towards the cranial edge of the proximal tip of the lateral condyle, often fading away near midshaft. This is a character also observed, for example, in Velociraptor, Microraptor, and Sinornithosaurus (Norell and Makovicky 1999, Hwang et al. 2002, X. Xu, unpublished data). The tibia is longer than the femur and it remains articulated with the fibula in the holotype, the latter being proximally wide. Below the proximal end, the fibula is sharply constricted to a very slender bony rod that reaches the ankle. The tibia is distally wide and fused to the astragalus. The ascending process of the astragalus covers the anterior surface of the distal portion of the tibia. The foot is subarctometatarsal (see Fig. 2B, 1) because the third metatarsal is proximally pinched between the second and fourth metatarsals, but remains visible in anterior and posterior views. This condition differs from the true arctometatarsal condition, in which metatarsal III is proximally wedged and transversely compressed between metatarsals II and IV, thus the proximal end of metatarsal III is not visible at anterior and posterior views (character 200 and 358 of $\mathrm{Hu}$ et al. 2009), as occurs in derived tyrannosaurids, ornithomi- 
mids, and troodontids (Holtz Jr. 2004, Makovicky and Norell 2004, Makovicky et al. 2004). However, the proximal most portion of the metatarsus of Buitreraptor is not preserved, so it is not possible to discern if metatarsals II and IV were proximally in contact to each other. Therefore, although metatarsal III is pinched proximally, it cannot be asserted if it was completely hidden beneath metatarsals II and IV in anterior view, as it was stated by $\mathrm{Hu}$ et al. (2009). The metatarsus (Fig. $2 \mathrm{~B}, 1, \mathrm{~m}$ ) is long, ca. $70 \%$ of the femoral length and ca. $67 \%$ of the tibial length (see Table I). By contrast, in Velociraptor, the metatarsus is only about $40 \%$ and $35 \%$ of the femoral and tibiotarsal length, respectively, while in Deinonychus these ratios are ca. $49 \%$ and ca. 45\%, respectively (Ostrom 1969, 1976c, Norell and Makovicky 1999). Accordingly, the metatarsal length of Buitreraptor, in comparison with the femoral and tibial lengths, is similar to that observed in Sinornithosaurus, Microraptor, and Bambiraptor (Xu et al. 1999, 2000, Burnham et al. 2000, Hwang et al. 2002, Burnham 2004, X. Xu, unpublished data). There is also similarities with troodontids, such as Sinovenator, Sinornithoides, and Saurornithoides (Xu et al. 2002, X. Xu, unpublished data), and with basal birds such as Archaeopteryx (Wellnhofer 1974, 1992, X. Xu, unpublished data), in which the length of the metatarsus, in comparison with the femoral length, varies between $70 \%$ and $80 \%$ approximately. Metatarsal III is the longest element of the metatarsus, whereas metatarsal II is slightly shorter than the IV. Metatarsals II and IV have a diameter similar to each other, unlike the condition observed in derived troodontids, in which metatarsal IV is the most robust (Xu et al. 2002, Makovicky et al. 2003). Metatarsals II and III have a partially developed ginglymoid distal articulation. The distal anterior surface of metatarsal III is slightly transversely expanded over the anterior surfaces of metatarsals II and IV. On the other hand, the distal posterior portion of metatarsals II and IV are expanded over the posterior surface of metatarsal III. The posterolateral surface of metatarsal IV is porteriorly projected as a sharp ridge (Fig. 2B, 1,m), resembling Microraptor, Sinornithosaurus, and Archaeopteryx (Xu et al. 1999, 2000, Hwang et al. 2002, Paul 2002, X. $\mathrm{Xu}$, unpublished data). The pedal phalanges are similar to those of other dromaeosaurids, with phalanx II-2 with a proximoventral flexor heel and a distal articulation dorsoventrally expanded. However, this phalanx is shorter and with a shaft not as constricted at midlength. Additionally, the ventral heel is less developed, when it is compared with more derived dromaeosaurids such as Dromaeosaurus, Velociraptor, Deinonychus, and Saurornitholestes (Matthew and Brown 1922, Colbert and Russel 1969, Ostrom 1969, Currie 1995, Norell and Makovicky 1997, Longrich and Currie 2009). Thus, it is morphologically more similar to the phalanx II-2 of Rahonavis, Microraptor, Sinornithosaurus, Graciliraptor, and some primitive troodontids (Forster et al. 1998, $\mathrm{Xu}$ and Wang 2000, Xu et al. 2002, X. Xu, unpublished data).

Unenlagia comahuensis Novas and Puerta, 1997

Materials: The holotype of Unenlagia comahuensis (MCF PVPH 78) (Figs. 1B and 3A) consists of an incomplete skeleton found in partial articulation, which includes three presacral vertebrae considered as the 8th, 10th, and 13th dorsals (the latter articulating to the sacrum), sacrum, dorsal ribs, two proximal haemal arches, left scapula and incomplete humerus, ilia, pubes, right ischium, right femur (found in direct association with the other elements), and left tibia (Novas and Puerta 1997). This theropod is medium-sized, approximately 2 meters in length.

Locality and horizon: Portezuelo Formation (late Turonian-early Coniacian), Sierra del Portezuelo region, Neuquén Province, Argentina (Fig. 1B, A). This geological sedimentary unit is composed of continental sediments, bearing frequent paleosol tops (Leanza et al. 2004). Apart from this species, this unit has provided other theropod species such as Patagonykus puertai Novas 1996, Megaraptor namunhuaiquii Novas 1998, a big undescribed coelurosaur (Coria et al. 2001), fragments of an abelisauroid (Novas 1996), and fragments of an undescribed Neornithes.

Main anatomical features and comments: Unenlagia comahuensis has been considered as one of the maniraptoran theropods most closely related to birds, sharing many anatomical features with basal birds, mainly with Archaeopteryx (Novas and Puerta 1997, Novas 2004).

Three presacral vertebrae are preserved, which are 


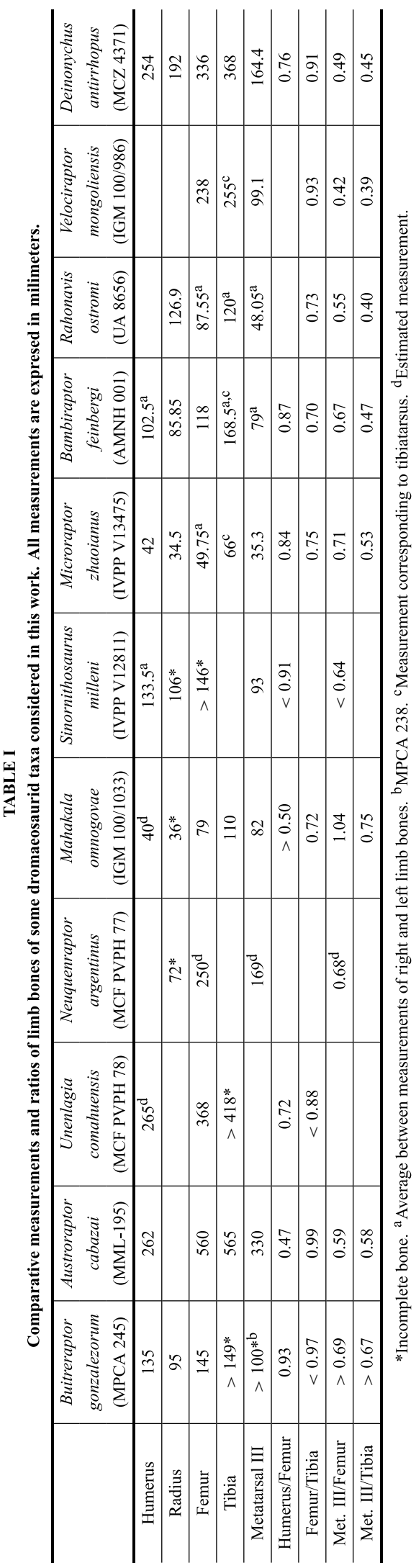



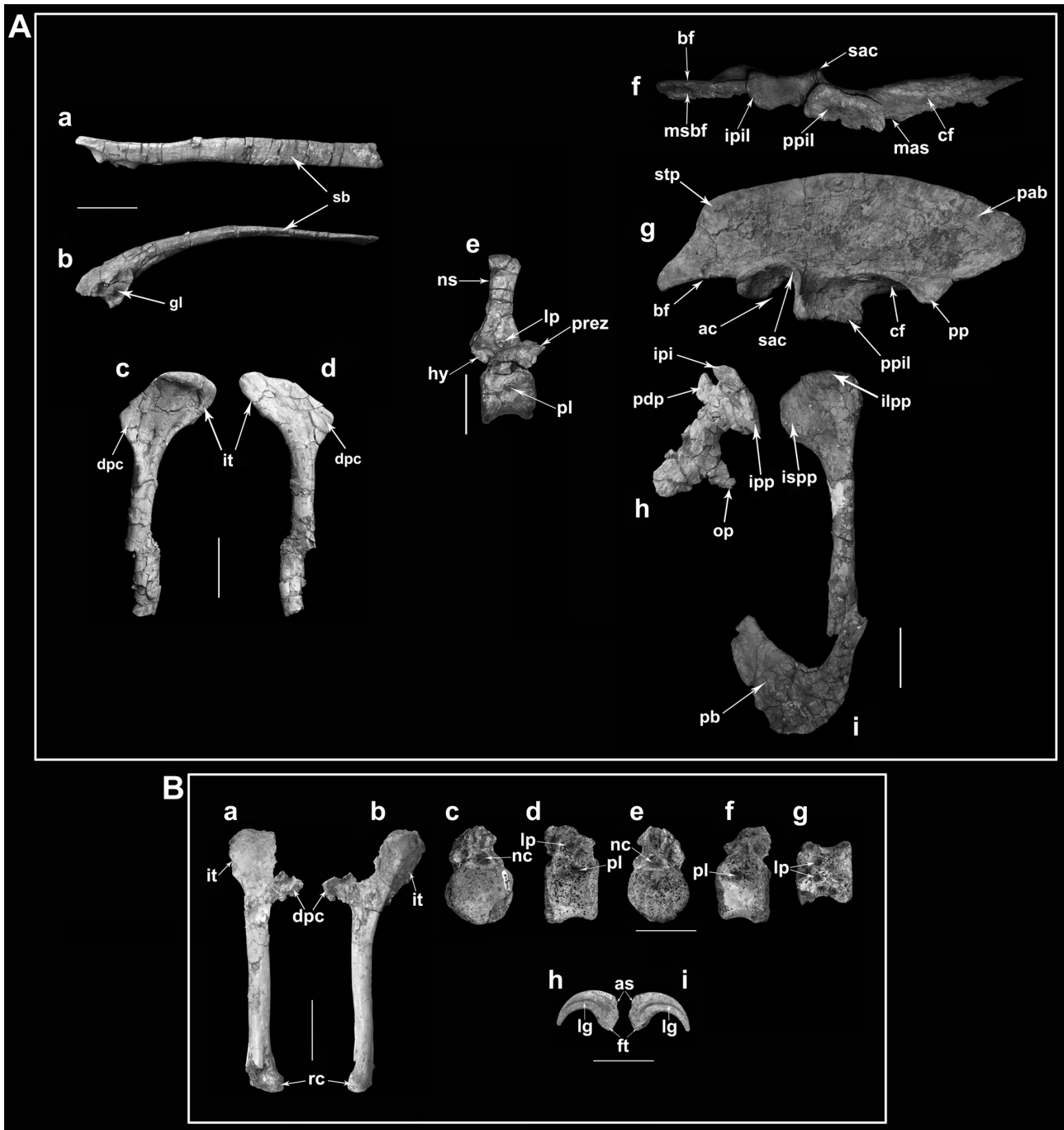

Fig. 3 - A: holotype of Unenlagia comahuensis (MCF PVPH 78); a and b: left scapula, in dorsal and lateral views; c and d: left humerus, in lateral and medial views; e: dorsal vertebra 13th?, in right lateral view; f-i: pelvic girdle; $f$ and g: left ilium, in ventral and lateral views; h; left ischium, in lateral view; i: left pubis, in lateral view. Scale bars: $5 \mathrm{~cm}$. B: Unenlagia paynemili; a-b: holotype (MUCPv-349); a and b: left humerus, in medial and lateral views; c-i: referred materials; c-g (MUCPv-416): dorsal vertebra, in anterior (c), right lateral (d), posterior (e), left lateral (f), and dorsal (g) views; h and i (MUCPv-343): manual ungueal, in lateral views. The remaining materials of the holotype and referred materials (MUCPv-409) are showed in Figure 4. Scale bars: $5 \mathrm{~cm}$. Abbreviations: the same of Figure 2, except: as, articular surface; cf, fossa for M. cuppedicus; ft, flexor tubercle; hy, hyposphene; ilpp, iliac process of the pubis; ipi, iliac process of the ischium; ipil, ischiadic process of the ilium; ispp, ischiadic process of the pubis; lg, lateral groove; lp, lateral pit; mas, medial antiliac shelf; msbf, medial shelf of the brevis fossa; nc, neural canal; pab, preacetabular blade; pb, pubic boot; pl, pleurocoel; pp, pendant process; ppil, pubic process of the ilium; rc, radial condyle; sac, supracetabular crest; sb, scapular blade; stp, supratrochanteric process. 
characterized by the presence of hyposphenes and pleurocoels on the dorsolateral surface of the centrum. The first of these vertebrae (considered as the 8 th dorsal) has an anteroventral heel on the centrum, similar but less developed than that present on the last cervicals and first dorsals of some dromaeosaurids such as Deinonychus (Ostrom 1969). The other dorsals preserved (the 10th? and the 13th) (Fig. $3 \mathrm{~A}$, e) of U. comahuensis have tall neural spines, which are anteroposteriorly expanded at its distal ends, being that of the anterior sacral more vertically elongated. A peculiar feature of the anterior sacral is the presence of deep lateral pits at the base of the neural spines (Fig. 3A, e) (Novas and Puerta 1997).

The sacrum consists of six fused vertebrae, although the ilia extend spanning the last two dorsal vertebrae anteriorly and the first caudal vertebra posteriorly (Novas and Puerta 1997). Six sacral vertebrae are also observed in dromaeosaurids such as Mahakala and Velociraptor (IGM 100/986) (Norell and Makovicky 1999, Turner et al. 2007), and troodontids such as Saurornithoides and Troodon (Forster et al. 1998, Rauhut 2003, Makovicky and Norell 2004, Norell and Makovicky 2004, Turner et al. 2007, Norell et al. 2009, P.J. Makovicky, unpublished data). On the other hand, the number of sacral vertebrae is five in the dromaeosaurids Saurornitholestes, Sinornithosaurus, and Microraptor (Norell and Makovicky 1997, Hwang et al. 2002, Rauhut 2003, X. $\mathrm{Xu}$, unpublished data), in the basal troodontids $\mathrm{Mei}$ long, Sinovenator and Sinusonasus magnodens (Xu and Norell 2004, Xu and Wang 2004, X. Xu, unpublished data), and in Archaeopteryx (Ostrom 1975, 1976b, Wellnhofer 1974, 1992).

In the original description of U. comahuensis, Novas and Puerta (1997) observed several avian traits in this dromaeosaurid, especially in the pectoral girdle, forelimb and pelvic bones. The general shape of the scapula (Fig. 3 A, a,b) is certainly quite similar to that of $A r$ chaeopteryx and Buitreraptor, with a twisted shaft, being strap-like in dorsal aspect and curved in lateral view (Novas and Puerta 1997, Novas 2009). Furthermore, the glenoid of Unenlagia was interpreted as laterally oriented, resembling the condition observed in birds (Novas and Puerta 1997, Norell and Makovicky 1999). This is in contrast to the more posteroventrally faced glenoid present in some dromaeosaurids, such as Deinonychus antirrhopus (Ostrom 1969, 1974). Nevertheless, a laterally oriented glenoid has also been observed in other dromaeosaurids, including, for example, Velociraptor mongoliensis (Norell and Makovicky 1999), Sinornithosaurus millenii (Xu et al. 1999, X. Xu, unpublished data), Bambiraptor feinbergi (Burnham et al. 2000, Burnham 2004), Tsaagan mangas (Norell et al. 2006), Rahonavis (Forster et al. 1998), and Buitreraptor (Makovicky et al. 2005), among others. The presence of a laterally oriented glenoid would have permitted a forelimb folding involving rotation of the humerus and also a more marked humeral abduction. Additionally, it would allow an almost vertical position of the forelimb during maximum upstroke, resembling the avian movements of the forelimb (Novas and Puerta 1997). However, Carpenter (2002) considered that the anatomical orientation of the scapula proposed by Novas and Puerta (1997) is wrong, i.e. the scapula of Unenlagia has been interpreted with its widest surface horizontally oriented, so the scapular blade results in a dorsoventrally compressed bone, instead of laterally compressed as predominantly observed in theropods (Carpenter 2002). If the scapula is oriented like a laterally compressed bone, with the costal surface medially oriented as in some articulated specimens of dromaeosaurids and other non-avian theropods, then the glenoid is oriented posteroventrally, not facing laterally (Carpenter 2002, Paul 2002, Senter 2006). On the other hand, in Rahonavis (Forster et al. 1998), a non-avian theropod with close anatomical affinities with Unenlagia (Novas 2004), the scapula might have been dorsally positioned on the ribcage, with the costal surface ventrally faced and lateral to the vertebral column, as occurs in avialans. This scapular position results in a more laterally facing glenoid. However, a lateralized position of the scapula and less dorsalized must be taken into account because the curvature of the scapula would match the curvature of the ribcage, and so the glenoid takes a more posteroventrally facing position. Additionally, the presence of a dorsally positioned scapula leads us to assume a large and flexed coracoid, like that observed in Buitreraptor, and the necessary presence of a sternum in Unenlagia, though one was not found. Unenlagia probably possessed a sternum, as many other dromaeosaurids (Burnham et al. 2000, Norell and Makovicky 1999, 2004, Xu et al. 1999, X. Xu, unpublished 
data), just based on its close phylogenetic position to Avialae. Nevertheless, placing the scapula in Buitreraptor as Carpenter (2002) explained, the coracoid takes an anatomically incorrect position, as its posteroventral portion pierces the thoracic cavity (Novas 2009). Despite the described situation, Unenlagia does not preserve coracoids. Therefore, the position of scapula and shape, ubication, and mode of articulation of the coracoid with the sternum (if the latter exists) are hypothetical. Nevertheless, the similarity among the scapulae of Archeopteryx, Buitreraptor and Unenlagia should be considered when analyzing the position of the scapula and the subsequent location of the glenoid. A more detailed analysis about the scapulocoracoid position and the subsequent orientation of the glenoid is beyond the objetive of this paper.

The humerus (Fig. 3A, c, d) has a well-developed and laterally projected deltopectoral crest, very similar to that of Buitreraptor, and also shows a large internal tuberosity that is proximodistally extended.

Recently, Novas (2004) considered further anatomical features with avian trends in Unenlagia, especially concerning features of the iliac morphology. In general shape, the ilium of Unenlagia (Fig. 3A, f, g) is anteroposteriorly elongated, although the postacetabular iliac blade is short and with the dorsal margin inflected, being convex anteriorly and concave posteriorly in lateral view (Novas and Puerta 1997). This ilium differs from that of other dromaeosaurids in some characters, and on the other hand presents similar features with the ilium of Rahonavis and early birds, such as Archaeopteryx and Confuciusornis (Novas 2004). As stated by Novas (2004), a preacetabular blade with an anteriorly expanded rounded border beyond a "pendant process" (Norell and Makovicky 1997), situated at the anteroventral corner of the ilium, is shared with Rahonavis, Archaeopteryx, Confuciusornis, and Patagopteryx (Novas 2004). By contrast, in other dromaeosaurids, the preacetabular blade is anterodorsally projected with respect to the pendant process, as in Deinonychus (Ostrom 1969, 1976c, Novas 2004) and Achillobator (Perle et al. 1999), or it is not anteriorly expanded, as in Bambiraptor (Burnham et al. 2000, Burnham 2004). A supratrochanteric process is observed on the dorsal edge of the ilium (Fig. 3A, g) above the acetabulum, in the form of a prominence that continues with a very shallow ridge that connects with the dorsal edge of the acetabulum. This process is also observed in Rahonavis (Forster et al. 1998), Archaeopteryx, Confuciusornis (Chiappe et al. 1999), and other early birds, but also in some dromaeosaurids such as Mahakala omnogovae and Hesperonychus elizabethae (Turner et al. 2007, Longrich and Currie 2009). The brevis fossa of Unenlagia is more reduced, transversely narrower, and anteroposteriorly shorter (Fig. 3A, f, and 4B, f) than in Buitreraptor and other dromaeosaurids, resembling the condition observed in early birds (Novas 2004). The ilium of $U$. comahuensis includes an inflection on the dorsal border of the iliac blade (Fig. 3A, g) close to the supratrochanteric process, and also a dorsally concave postacetabular blade, the latter feature shared also with Rahonavis and Buitreraptor (Forster et al. 1998, Novas 2004, Makovicky et al. 2005), while in other dromaeosaurids the postacetabular blade is convex (e.g. Velociraptor, Bambiraptor, Deinonychus, and Mahakala) (Ostrom 1969, 1976c, Norell and Makovicky 1997, 1999, Burnham et al. 2000, Burnham 2004, Turner et al. 2007). A similar inflection of the dorsal border of the postacetabular process is observed in Microraptor and Hesperonychus (Hwang et al. 2002, Longrich and Currie 2009), but, in both taxa, the postacetabular blade between the inflection point and the tip of the blade is not concave, but straight. A medially constricted acetabulum is present (Novas and Puerta 1997, Novas 2004), as in Hesperonychus and Buitreraptor (Makovicky et al. 2005, Longrich and Currie 2009). Another feature is the anteroventral inclination of the pubic peduncle, but this feature is widely observed in many dromaeosaurids including Adasaurus, Velociraptor, Microraptor, Mahakala, Hesperonychus, and also Rahonavis (Barsbold 1983, Norell and Makovicky 1997, 1999, Forster et al. 1998, Hwang et al. 2002, Turner et al. 2007, Longrich and Currie 2009). By contrast, in Deinonychus and some early birds (i.e., Archaeopteryx, Confuciusornis, and enanthiornitines), this peduncle has a posteroventral inclination (Ostrom 1969, 1976c, Wellnhofer 1993, Chiappe et al. 1999, Novas 2004). In Unenlagia the supracetabular crest is prominent, particularly its anterior portion, resembling the condition of Buitreraptor, while generally in dromaeosaurids the crest is shallower, 
like that seen in Microraptor, Velociraptor, and Deinonychus (Ostrom 1969, 1976c, Norell and Makovicky 1997, 1999, Hwang et al. 2002). In addition, the anterior rim of the acetabulum of $U$. comahuensis is laterally projected, in similar way to that of Hesperonychus (Longrich and Currie 2009).

The pubis of Unenlagia comahuensis (Fig. 3A, i, and $4 \mathrm{C}, \mathrm{b}, \mathrm{d}$ ) is long, slightly shorter than the femur, and ventrally projected, resembling the condition of Deinonychus, Rahonavis, Buitreraptor, and Archaeopteryx (Ostrom, 1976c, Forster et al. 1998, Makovicky et al. 2005), but differing from the more posteroventraly oriented pubis of many maniraptorans. The pubic shaft is straight and medially expanded forming the pubic apron, which extended approximately along $3 / 4$ of the length of the bone (Fig. 4C, d). It differs from that of Velociraptor, Bambiraptor, Microraptor, and Sinornithosaurus, in which it is extended about half the length of the pubis (Norell and Makovicky 1997, Burnham et al. 2000, Xu et al. 2000, Hwang et al. 2002, Burnham 2004, X. $\mathrm{Xu}$, unpublished data). Distally, the pubes are fused to a symphysis, and a transversely compressed pubic boot is present (Fig. 3A, i). It is slightly inclined posteriorly and short in anteroposterior direction, being devoid of an anterior process and tapering posterodorsally to end in a blunt tip, thus resembling that of Bambiraptor (Burnham et al. 2000, Burnham 2004).

The ischium (Fig. 3A, h) is poorly preserved when compared with the rest of the pelvic bones. It is platelike and short, as commonly observed in maniraptorans, and it bears an anteriorly projected and pointed distal obturator process, resembling Sinornithosaurus and Buitreraptor (Xu et al. 1999, Makovicky et al. 2005, X. Xu, unpublished data). A proximodorsal process, similar to that of Buitreraptor, is also present.

The femur of Unenlagia is elongated and slender, as in Microraptor, Bambiraptor, and Buitreraptor. It has a small proximal head and lacks the fourth trochanter, as occurs in Sinornithosaurus and Microraptor (Burnham et al. 2000, Burnham 2004, Novas 2004, Makovicky et al. 2005, X. Xu, unpublished data). Both femoral features are also observed in Rahonavis and Archaeopteryx (Forster et al. 1998, Novas 2004). The anterior trochanter is proximally projected similarly to that of Buitreraptor and Rahonavis (Novas 2009). The tibia is also a slender bone, longer than the femur (see Table I), with a transversely expanded distal articular portion.

Unenlagia paynemili Calvo, Porfiri and Kellner, 2004

Materials: The holotype of Unenlagia paynemili (MUCPv-349) (Fig. 1B; 3B; and 4C, a, c) consists of a left femur and a left pubis. Referred specimens are a dorsal vertebra (MUCPv-416) (Fig. 3B, c-g), the posterior end of a right ilium (MUCPv-409) (Fig. 4B, b, d, g), one pedal phalanx (MUCPv-415), and a manual claw (MUCPv-343) (Fig. 3B, h, i).

The materials belonging to the holotype were found disarticulated but in close association. The ilium was collected 23 meters from the pubis, but with the same bone color, kind of preservation and size of the holotype. The phalanges and the ungual were also found isolated and between 5 and 15 meters from the pubis. The dorsal vertebra was found next year following the original discovery of the holotype, by surface collecting, so it is interpreted as it has been washed out from the quarry during the flooding of Barreales Lake (Calvo et al. 2004).

Locality and horizon: Futalognko site, placed at Costa Dinosaurio Locality, northern coast of the Barreales Lake, northeastern Neuquén Province (Calvo et al. 2004) (Fig. 1A). The fossil-bearing beds of this locality are included in the Portezuelo Formation (Fig. 1B), the same geological unit of procedence of Unenlagia comahuensis. Among other tetrapods found at this locality are titanosaurian sauropods, theropods, ornithopods, turtles, osteichthyan fishes, crocodylomorphs, and pterosaurs (Calvo et al. 2004). The holotype of Unenlagia paynemili was discovered during a fieldtrip in 2002, and additional remains in 2003 also from continental deposits from the top of the Portezuelo Formation (Calvo et al. 2004).

Main anatomical features and comments: Several anatomical similarities are certainly found between the theropod from the Futalognko site and U. comahuensis (see Fig. 4). However, the former also presents some minor traits that support the specific differentiation given by the authors (Calvo et al. 2004). In general parameters, the bones of $U$. paynemili are more gracile than those of $U$. comahuensis. The humerus of $U$. paynemili 


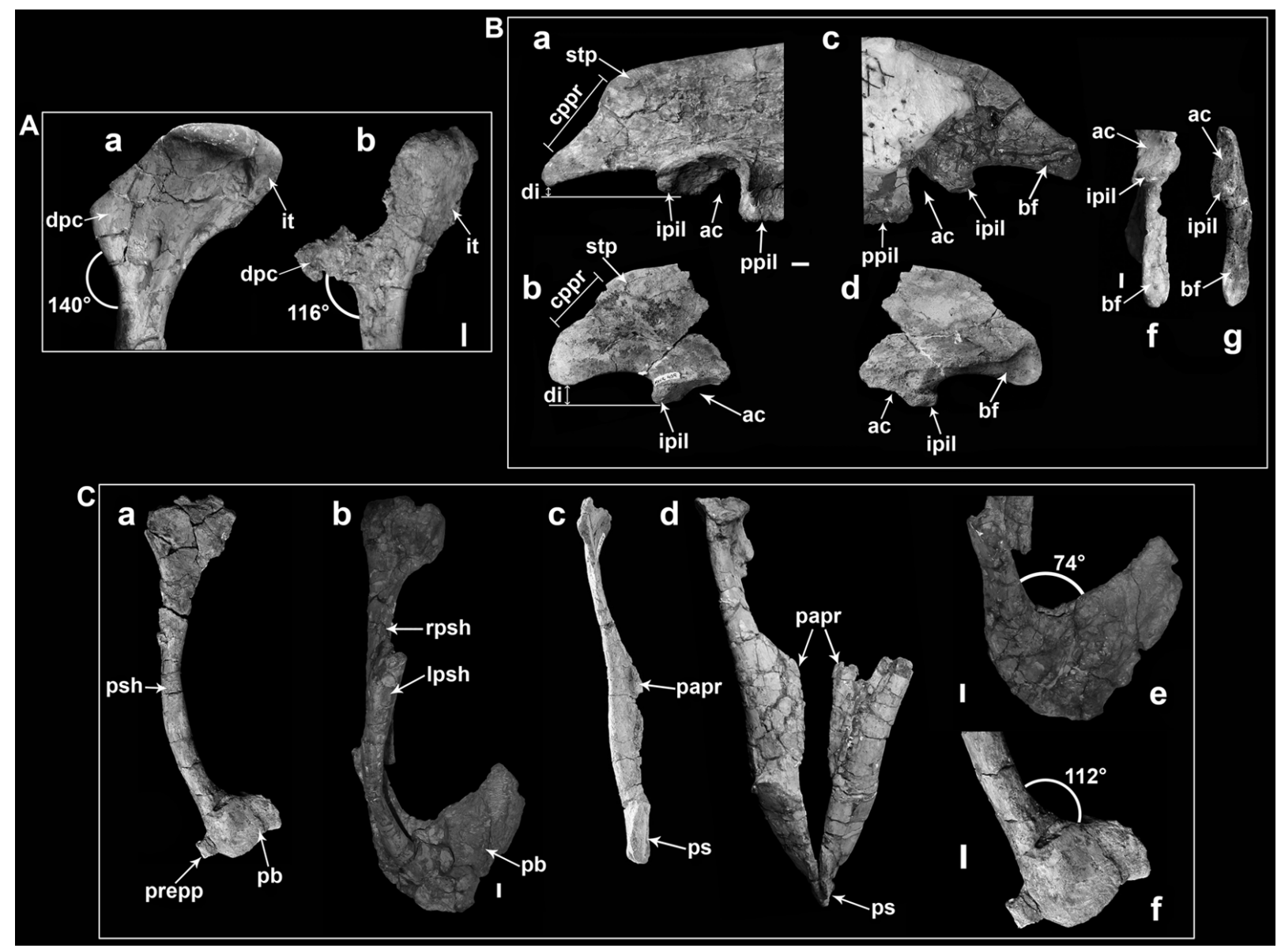

Fig. 4 - Osteological comparison between U. comahuensis and U. paynemili; those differences discussed by Calvo et al. (2004) and those discussed in this paper are included. A: comparison of the proximal part of the left humerus of U. comahuensis (a) and U. paynemili (b) (observe the eroded surface of the deltopectoral crest); the angle between the deltopectoral crest and the shaft is marked. B: comparison of the posterior part of the ilium of $U$. comahuensis (a, c, e) and U. paynemili (referred material: MUCPv-409) (b, d, f); a and b: lateral views; c and d: medial views; e and f: ventral views. C: comparison between the pubes of $U$. comahuensis (b, d, e) and U. paynemili (holotype: MUCPv-349) (a, c, f); a: left pubis of $U$. paynemili, in lateral view (the supposed prepubic process is marked) ; b: pubes of $U$. comahuensis, in left lateral view; c and d: left pubis of $U$. paynemili and pubes of $U$. comahuensis, in posterior view; e: pubic boot of the right pubis of $U$. comahuensis, in medial view; d: pubic boot of the left pubis of $U$. paynemili, in lateral view. The angle between the pubic boot and the shaft of the pubis is marked. Scale bars: $1 \mathrm{~cm}$. Abbreviations: in A the same of Figure 2. In B the same of Figure 3, except: cppr, concavity of the posterior rim of the postacetabular blade; di, distance between the tip of the postacetabular blade and the tip of the ischiadic process of the ilium. C: lpsh, left pubic shaft; papr, pubic apron; pb, pubic boot; prepp, prepubic process; ps, pubic symphysis; psh, pubic shaft; rpsh, right pubic shaft.

(Fig. 3B, a, b) is almost complete, but its proximal and distal ends are poorly preserved. The proximal end of this bone is deflected relative to the longitudinal axis of the shaft, in a similar way to that in $U$. comahuensis. Nevertheless, the differences between $U$. comahuensis and U. paynemili exposed by Calvo et al. (2004) are the smaller size of the humerus (about $20 \%$ smaller), a smaller angle between the ventral margin of the del- topectoral crest and the humeral shaft $\left(116^{\circ}\right.$ in $U$. paynemili; $140^{\circ}$ U. comahuensis), and the presence in $U$. comahuensis of a ridge on the dorsal margin posterior to the deltopectoral crest, not observed in U. paynemili (Fig. 4A). However, the poor degree of preservation of the deltopectoral crest of $U$. paynemili makes it difficult to precisely measure the angle between the shaft and the crest. Moreover, the presence of a ridge on the 
dorsal margin posterior to the deltopectoral crest is difficult to ascertain with certainty, because the surface of the crest is severely eroded (F.A. Gianechini, personal observation).

The pubis of $U$. paynemili (Fig. 4C, a, c) is a slender bone, with the distal half of the shaft curved posteroventrally, resembling the common condition of Dromaeosauridae. Distally, both pubes are fused along the midline forming a pubic boot, which is broken at the posterior end. Anteriorly, the pubic boot has a small projection, which was considered to be a prepubic process (Fig. 4C, a, f). This process has its dorsal and ventral surfaces broken, but a continuity between the lateral and medial surfaces of the pubic boot and these surfaces of the process is observed (F.A. Gianechini, personal observation). Therefore, it is possible to consider it as a true prepubic process. Another difference from $U$. comahuensis is a greater angle between the shaft and the proximal dorsal rim of the posterior process of the pubic boot (Fig. 4C, e, f). In U. comahuensis there is a more pronounced angle in this sector, with a pubic boot very inclined posterodorsally forming a pubic cup, as in Bambiraptor (Burnham et al. 2000, Burnham 2004). The pubic apron of the left pubis extends medially (Fig. 4C, c), but without contact with the opposing pubic apron, despite the fact that both pubes would have fused distally at the zone of pubic boot similarly to the pubes of $U$. comahuensis. Nevertheless, the pubic apron of $U$. paynemili extends from about half the length of the pubic shaft to the distal part, thus starting more distally with respect to U. comahuensis. Moreover, the proximal part of the shaft is narrower and more slender than in $U$. comahuensis (Fig. $4 \mathrm{C}, \mathrm{c}, \mathrm{d}$ ). Another difference arises in the angle between the dorsal border of the pubic apron and the medial border of the pubic shaft, which is greater in U. paynemili (Fig. $4 \mathrm{C}, \mathrm{c})$. Although in general appearence the pubes of $U$. paynemili and $U$. comahuensis are very similar to each other, it is not possible to certainly assert if the pubis of $U$. paynemili was vertically oriented, as in $U$. comahuensis, because the entire preacetabular portion of the ilium is not preserved. However, in Bambiraptor the pubis is similar to that of Patagonian genera, being posteroventrally inclined (Burnham et al. 2000, Burnham 2004). The posteroventral curvature of the distal part of the pubic shaft was considered as an autopomorphy of Unenlagia by Novas and Puerta (1997), but a later contribution indicated that the pubis of $U$. comahuensis is also posteroventrally curved as in U. paynemili (Calvo et al. 2004) (Fig. 4C, b), and this character is also present in Buitreraptor. This curvature is better observed in the left pubis of $U$. comahuensis because the right one is broken and the distal part is displaced from its original position. Another similarity between both taxa is the presence of a sigmoid lateral border of the pubic shaft in posterior view, with a proximal part slightly concave while the distal third has a convex border (Fig. 4C, c, d). This character is more pronounced in $U$. paynemili and is considered synapomorphic of the genus Unenlagia (Calvo et al. 2004). The pubic boot in $U$. paynemili was interpreted similarly to that of U. comahuensis (Calvo et al. 2004, Fig. 12, pag. 555), but its distal portion is missing.

The postacetabular blade of the ilium of $U$. paynemili (Fig. 4B, b, d) has an acuminate end like in other Maniraptora. The dorsal margin, posterior to the acetabulum, has a marked inflection and the posterodorsal border behind the inflection is concave as in U. comahuensis, Buitreraptor, and Rahonavis. In the inflection zone there is a rugose area, which may correspond to the supratrochanteric process observed in $U$. comahuensis (Novas and Puerta 1997), and was interpreted as a muscle attachment zone (Calvo et al. 2004). Such inflection in the margin of the postacetabular blade, a putative synapomorphic character of Unenlagia, is also present in some microraptorine dromaeosaurids such as Microraptor and Hesperonychus, and also (though less conspicuous) in Velociraptor (Norell and Makovicky 1997), but the dorsal rim is straight posterior to the inflection point, and not concave as is observed in Unenlagia. On the other hand, in Deinonychus, Bambiraptor, Luanchuanraptor, Tianyuraptor, Mahakala, in troodontids such as Sinovenator and Anchiornis, and in basal birds such as Archaeopteryx, Jeholornis, and Confuciusornis, the dorsal rim of the postacetabular blade is convex and continuous with the dorsal rim of the preacetabular blade, without the presence of any point of inflection (Ostrom 1969, 1976b, Wellnhofer 1974, 1992, Chiappe et al. 1999, Burnham et al. 2000, Elzanowski 2002, Paul 2002, Zhou and Hou 2002, Zhou and Zhang 2002, 
2003. Burnham 2004, Lü et al. 2007, Turner et al. 2007, Hu et al. 2009, Xu et al. 2009, Zheng et al. 2010, X. Xu, unpublished data). Furthermore, in Microraptor, Hesperonychus, and Archaeopteryx a supratrochanteric process is also present (Ostrom 1969, 1976b, Wellnhofer 1974, 1992, Elzanowski 2002, Hwang et al. 2002, Longrich and Currie 2009). In U. paynemili, in comparison with $U$. comahuensis, the end of the postacetabular blade is more rounded, and the postacetabular entire blade is less posteroventrally inclined, so that its posterior end is situated above the level of the ventral end of the ischiadic peduncle (Fig. 4B, a, b). By contrast, in $U$. comahuensis the posterior end of the postacetabular blade is situated at almost the same level of the ventral end of this peduncle. Moreover, the posterior portion of the acetabulum is more open in U. paynemili, and it is not separated from the brevis fossa by a ridge, as occurs in $U$. comahuensis (Calvo et al. 2004). Furthermore, in $U$. paynemili the brevis fossa shallower and its medial shelf is less developed with respect to that of $U$. comahuensis (Fig. 4B, c, d).

The dorsal vertebra (MUCPv-416) (Fig. 3B, c-g), corresponding to the referred material, consists of a centrum and the base of the neural arch. This vertebra has a lateral pit close to the base of the neural spine, on each side (Fig. 3B, d, g), a feature also present in the posterior dorsal vertebrae of $U$. comahuensis (Novas and Puerta 1997, Calvo et al. 2004). On the dorsolateral portion of the centrum and close to the base of the neural arch, on each side, there is a pleurocel, and posteriorly to this pleurocel and slightly ventrally, a small depression is ubicated (Fig. 3B, d, f). On the ventral side of the centrum there is a shallow longitudinal groove, followed by a small foramen (Calvo et al. 2004). The parapophyses are laterally projected, a common feature among the Dromaeosauridae, and are situated on the neural arch (Calvo et al. 2004).

The remaining referred materials include one pedal phalanx (MUCPv-415) and an ungual manual phalanx (MUCPv-343). The pedal phalanx MUCPv-415 was interpreted as the first phalanx of the right digit I (Calvo et al. 2004), but in a later contribution (Porfiri and Calvo 2007) the same phalanx was correctly reinterpreted as the first of the pedal digit II. It has a ginglymoid distal articulation, with asymmetric condyles, being the lateral one slightly larger, separated by a deep groove. For its part, the proximal articulation is formed by two asymmetric concave surfaces, being the lateral surface slightly larger, and both are separated by a ridge (Calvo et al. 2004). The general form of this phalanx resembles that of the phalanx II-1 of other dromaeosaurids, such as Velociraptor (Norell and Makovicky 1997). It has a proximal end with asymmetric medial and lateral concave surfaces, being the medial surface larger than the lateral one, and both are divided by a blunt ridge (Calvo et al. 2004). The ventral rim of this end is slightly more proximally projected than the dorsal rim, thus forming a small tongue-like process, which in Velociraptor overlaps the trochlea of metatarsal II (Norell and Makovicky 1997).

There is a ridge extended from this tongue, which reaches another ridge present in the trochlea of the distal articulation, and which was considered as lying on the dorsal surface by Calvo et al. (2004). The shaft is dorsoventrally constricted close to the distal articulation. The latter is distinctly ginglymoid, almost circular in lateral view, and dorsally extended, with two large medial and lateral trochleae separated by a deep median groove. The form of the distal articulation confers a wide angle of movement to the phalanx II-2, with a great degree of extension of the latter (Ostrom 1969). In Velociraptor, the ridge on the ventral surface of the phalanx II-1 extends from the proximal articulation to the medial distal condyle, a condition that is considered here as present in $U$. paynemili. The lateral distal condyle is transversely wide and shows a sub-circular fossa on the lateral side for attachment of the collateral ligaments. The medial condyle is narrower and presents a much less developed fossa on the medial side. The pits for the collateral ligaments are usually dorsally displaced in dromaeosaurids, and a slight displacement is observed in U. paynemili. An asymmetric development of the condyles of the distal articulation, with a narrower medial condyle and a wider lateral one, is also observed in Sinornithosaurus and Microraptor (Xu et al. 1999, 2000, X. Xu, unpublished data).

The ungual phalanx (MUCPv-343) (Fig. 3B, h, i) is strongly curved and laterally compressed, with a proximal articulation formed by two shallow surfaces divided by a blunt ridge and a strong flexor tubercle in the prox- 
imal end below the articular facets (Calvo et al. 2004). On each side, there is a groove extending through the medial part of this phalanx from the flexor tubercle, but not from the proximal edge. This groove follows the curvature of the ventral rim of the claw and reaches the dorsal margin close to the tip (Calvo et al. 2004). Two additional grooves in the proximal region, on one side (lateral or medial undetermined), have been observed by Calvo et al. (2004). This kind of trait is also observed in Sinornithosaurus and Troodon (Russel 1969, X. Xu, unpublished data). Following the overall morphology of the claw, Calvo et al. (2004) related this element to the ungual phalanx of digit I of Rahonavis. However, more recently, Porfiri and Calvo (2007) attributed this to a manual ungual, an assignment that is followed here. In this regard, the poor extension of the articular facets of this claw indicates that it is a manual ungual phalanx. The manual claws are also very curved and have a strong flexor tubercle, but contrasting with the pedal claws, the proximal articular surface has a minor dorsoventral extension, more dorsally situated, and less concave and defined (Novas et al. 2005, Senter 2007). In addition, the flexor tubercle of the manual claws is more ventrally projected, as observed in the claw of $U$. paynemili (Colbert and Russel 1969, Ostrom 1969, Sues 1978, Kirkland et al. 1993, Forster et al. 1998, Norell and Makovicky 1999, Xu et al. 1999, 2000, Allain and Taquet 2000, Burnham et al. 2000, Burnham 2004, Longrich and Currie 2009, X. Xu, unpublished data).

\section{Neuquenraptor argentinus Novas and Pol, 2005}

Materials: the holotype of Neuquenraptor argentinus (MCF PVPH 77) (Fig. 1B, and 5A, B) consists of a fragmentary cervical vertebra, dorsal ribs, haemal arches, left proximal radius, right femur, left distal tibia, left proximal tarsals, and an almost complete left foot. The total length of the holotype has been estimated in ca. 2 $\mathrm{m}$. All of these materials were found partially articulated and associated with sauropod bones.

Additional materials referred to this taxon were found more recently, which consists in an articulated left foot (MUCPv-1163) comprising a complete metatarsus and digits, together with undetermined fragments of bone (Porfiri et al. 2007).

Locality and horizon: Portezuelo Formation (Conia- cian), Sierra del Portezuelo, Neuquén Province, Argentina (Fig. 1B). The additional materials were found at Baal quarry, north Coast of Barreales Lake, Neuquén Province, and also come from the Portezuelo Formation. The geological features and paleontological records of this unit have already been discussed above, in the section of locality and horizon of provenance of $U$. comahuensis and U. paynemili.

Main anatomical features and comments: The only forelimb bone recovered is the proximal portion of a left radius (Fig. 5A, a, b). This bone is slender and long, as in other deinonychosaurs, and it has a proximal articular surface triangular in contour (Fig. 5A, b), as is the case in Saurornitholestes langstoni, Deinonychus, Bambiraptor, and Buitreraptor (Ostrom 1969, Burnham 2004, Makovicky et al. 2005, Novas and Pol 2005).

The femur is incomplete and the proximal and distal articular ends are absent (Fig. 5A, c, d). Nevertheless, Novas and Pol (2005), from the preserved portion of the shaft, interpreted that this bone is proportionally short and robust, resembling the condition of Saurornitholestes, but differing from the longer and slender femur of most deinonychosaurs and avialans, including U. comahuensis (Novas and Puerta 1997, Novas and Pol 2005). However, Makovicky et al. (2005, supplementary information) considered that, even similar in size and robustness, there are no substancial differences between the femora of $U$. comahuensis and Neuquenraptor. Nevertheless, the preservation of the femur of Neuquenraptor is quite poor, limiting any attempt of comparison with the femur of $U$. comahuensis. Only the distal ends of the left tibia and fibula are preserved (Fig. 5A, e, f). The fibula is distally splint-like, similar to that of Buitreraptor (Makovicky et al. 2005). Proximal left tarsals are present (Fig. 5A, e, f), with a calcaneum being transversely compressed. The astragalus has preserved only part of the ascending process (Novas and Pol 2005).

A subarctometatarsal condition is observed in the pes of Neuquenraptor (see Fig. 5A, g, i), as occurs in several dromaeosaurids such as Buitreraptor, Microraptor zhaoianus, Microraptor gui, Bambiraptor, Graciliraptor, Sinornithosaurus, and Sinovenator (Xu et al. 1999, 2000, 2003, Xu and Wang 2000, Burnham 2004, 
Makovicky et al. 2005, X. Xu, unpublished data). In this regard, the proximal portion of metatarsal III of Neuquenraptor is slightly transversely pinched between metatarsals II and IV, and the distal portion expands over the anterior surfaces of metatarsals II and IV (Fig. 5A, $\mathrm{g}, \mathrm{i})$. On the other hand, the distal posterior surface of metatarsal III is covered by lateral and medial projections of metatarsals II and IV, respectively (Novas and Pol 2005) (Fig. 5A, g, i). The lateral expansion of metatarsal II over the posterior surface of metatarsal III was considered as an autopomorphy of Neuquenraptor (Novas and Pol 2005). However, Buitreraptor shares this character with Neuquenraptor (Novas 2009). Metatarsals II and IV are sub-equal in length, both with the distal end approximately at the same level (Fig. 5A, $\mathrm{g}, \mathrm{i}$ ), but metatarsal II is transversely wider than metatarsal IV, as occurs in Graciliraptor, Sinornithosaurus, and Microraptor (Xu et al. 1999, 2000, Hwang et al. 2002, Makovicky and Norell 2004, X. Xu, unpublished data), differing from the condition observed in derived troodontids, in which metatarsal IV is more robust than metatarsal II. The distal portion of metatarsal II is ginglymoid, as is common among dromaeosaurids, whereas metatarsal III has an incipient ginglymoid distal articulation (Novas and Pol 2005). The lateral and medial condyles of metatarsal III are not well developed and separated by a shallow groove, thus resembling the condition of Buitreraptor, Sinornithosaurus, Microraptor, Graciliraptor, Rahonavis and Sinovenator (Forster et al. 1998, X. Xu, unpublished data), and differing from the better developed distal ginglymoid of metatarsal III present in more derived dromaeosaurids, such as Velociraptor and Deinonychus (Ostrom 1969, Norell and Makovicky 1997). Metatarsal IV is characterized by the presence of a well-developed and sharp longitudinal flange ubicated in the posterolateral surface of the shaft, which is posteriorly projected, extending approximately from the mid-length of the shaft to near the distal articulation of the bone (Fig. 5A, h, i). This flange is also present in Microraptor, Sinornithosaurus, Buitreraptor, and in the troodontids Sinornithoides and Sinovenator (Xu et al. 1999, 2000, Xu and Wang 2000, Hwang et al. 2002, Makovicky et al. 2005, Novas and Pol 2005, $\mathrm{X}$. Xu, unpublished data). Metatarsal III of Neuquenraptor also has an extensor sulcus on the anterior sur- face, as in Sinovenator and Buitreraptor (Makovicky et al. 2005, X. Xu, unpublished data), which could correspond to the extensor distal fossa. The metatarsus/femur ratio among Neuquenraptor, Buitreraptor, and microraptorines (see Table I) is similar, indicating the presence of an elongated metatarsus for Neuquenraptor and the other taxa.

The phalanges of Neuquenraptor (Fig. 5A, j-m; 5B) show general features widespread among deinonychosaurs, especially those of the second pedal digit. Thus, phalanx II-1 shows a proximal articulation surface formed by two lateral and medial depressions. It also shows a ridge between them, and a distal ginglymoid articulation very expanded dorsoventrally (Fig. 5A, k; $5 \mathrm{~B})$. The shaft of this phalanx is slender and dorsoventrally constricted close to the distal end. Ventrally, a ridge is extended from the proximal articulation through the medioventral surface until the medial condyle of the distal articulation (Fig. 5B, h). The medial condyle presents a lesser developed collateral ligament pit than the lateral condyle (Fig. 5B, e). The morphology of the phalanx II-1 of Neuquenraptor is almost identical to that of Unenlagia paynemili (Makovicky et al. 2005, supplementary information) (see Fig. 5B). Phalanx II2 bears a proximoventral heel, but not developed in the same degree observed in most derived dromaeosaurids (Longrich and Currie 2009), with a shaft constricted dorsoventrally and a distal ginglymoid dorsoventrally expanded (Fig. 5A, k). The constriction of the shaft is narrower than in basal dromaeosaurids, including Sinornithosaurus, Microraptor, and Graciliraptor (Xu et al. 1999, 2000, Hwang et al. 2002, X. Xu, unpublished data), but it does not reach the constriction grade of more derived dromaeosaurids, such as the Velociraptorinae and Dromaeosaurinae. The proximoventral heel is triangular both in dorsal and ventral views, and more robust on the medial side, as usually occurs among deinonychosaurs. Phalanges II-1 and II-2 are subequal in length, while in Unenlagia paynemili the phalanx II-1 is slightly longer than phalanx II-2, resembling the usual condition of troodontids ( $\mathrm{Xu}$ and Wang 2000, Porfiri and Calvo 2007). The ungual phalanx of the digit II is strongly curved, with a strong proximoventral flexor tubercle (Fig. 5A, k). One groove is situated on each side of this ungual phalanx, the lateral 

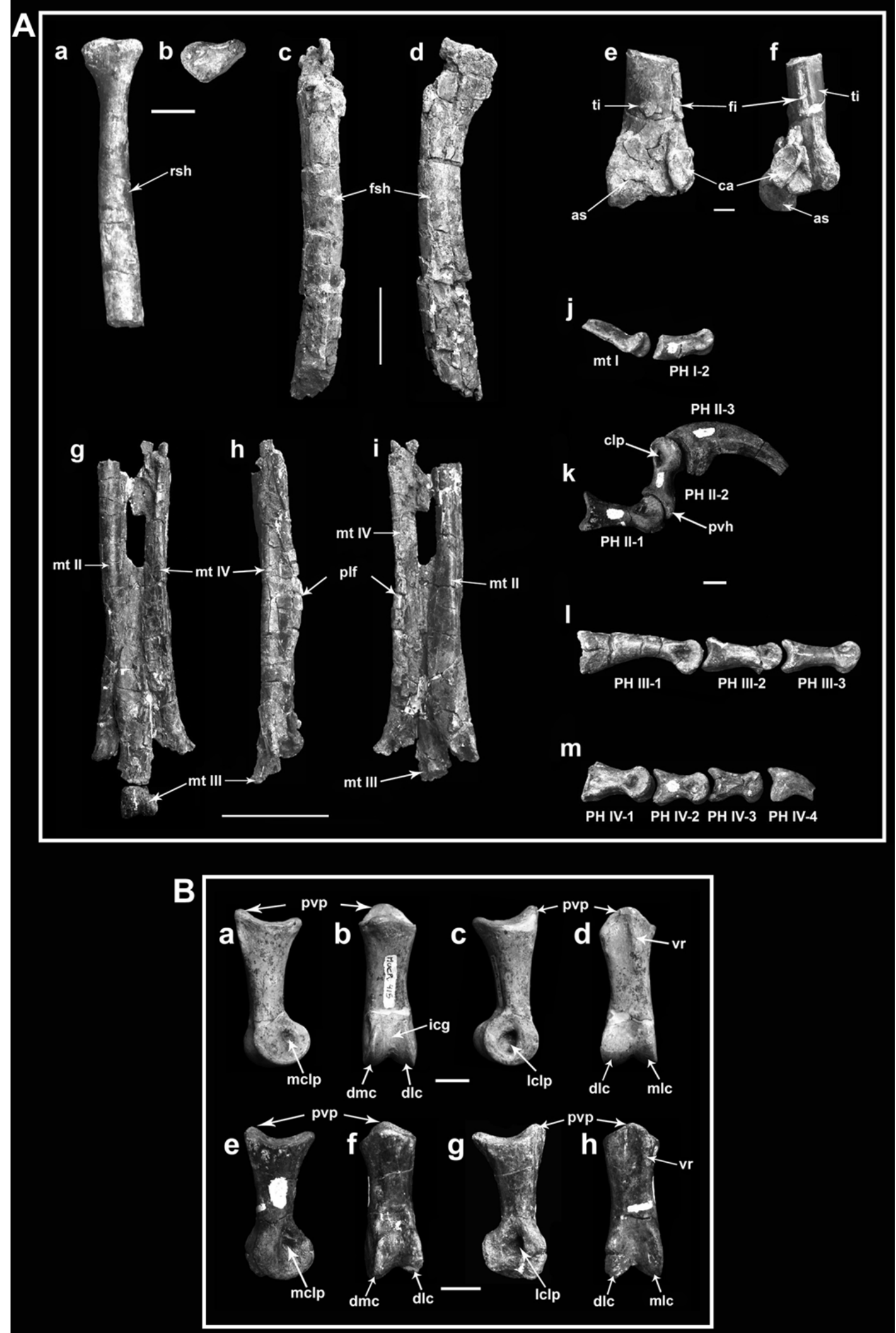
Fig. 5-A: holotype of Neuquenraptor argentinus (MCF PVPH 77); a and b: proximal part of the left radius, in lateral and proximal articular views; c and d: right femur, in lateral and anterior views; e and f: distal portion of the left tibia, and tarsus, in anterior and lateral views; g-i: left metatarsus, in anterior (g), lateral (h), and posterior (i) views; $\mathrm{j}-\mathrm{m}$ : pedal digits of the left pes, all in medial view; $\mathrm{j}$ : digit $\mathrm{I}$; k: digit II; 1 : digit III; m: digit IV. Scale bars: $1 \mathrm{~cm}$ for radius, tibiotarsus, and digits; $5 \mathrm{~cm}$ for femur and metatarsus. B: comparison between phalanges II-1 of $U$. paynemili (MUCPv-415) and N. argentinus (MCF PVPH 77), in lateral (c, g), medial (a, e), dorsal (b, f), and ventral views (d, h). Abbreviations: as, astragalus; ca, calcaneum; clp, collateral ligament pit; dlc, distal lateral condyle; dmc, distal medial condyle; fi, fibula; fsh, femoral shaft; icg, intercondylar groove; lclp, lateral collateral ligament pit; mclp, medial collateral ligament pit; mt I, metatarsal I; PH, phalanx; pvh, proximoventral heel; pvp, posteroventral process; rsh, radial shaft; ti, tibia; vr, ventral ridge. Metatarsus: the same abbreviations of Figure 2.

one situated more dorsally than the medial one. However, it does not exhibit the strong asymmetric disposition observed in derived dromaeosaurids, with the lateral groove dorsally displaced and the medial more ventral, such as in Saurornitholestes, Velociraptor, Deinonychus, and Utahraptor (Ostrom 1969, Sues 1978, Kirkland et al. 1993, Norell and Makovicky 1997, 1999, Longrich and Currie 2009). The pedal ungual phalanges III-4 and IV-5 resemble those of other deinonychosaurs, being less curved than the claw of the second digit, without lateral and medial grooves and without strong flexor tubercles.

The additional materials from Barreales Lake present a number of features shared with the holotype, like phalanges 1 and 2 subequal in length, a subarctometatarsal condition with metatarsal III pinched proximally between metatarsals II and IV, metatarsal IV with a posterolateral flange, an extensor sulcus on the proximal half of metatarsus, distal end of metatarsal III with a poorly developed ginglymoid compared with that observed in Laurasian dromaeosaurids, and metatarsal II with a lateral expansion over the posterior surface of metatarsal III (Porfiri et al. 2007). Except by the subequal length of phalanges 1 and 2 of the second digit, the remaining characters are also present in Buitreraptor. Moreover, some variations have been indicated in the proportions of the phalanges of the digit II, which have been attributed to a probable subadult stage of the specimen from Barreales Lake (Porfiri et al. 2007). Accordingly, the assignment of this material to Neuquenraptor is considered here as tentative.

\section{Austroraptor cabazai}

Novas, Pol, Canale, Porfiri and Calvo, 2009

Materials: the holotype (MML-195) (Fig. 1B, and 2A) includes both cranial and postcranial remains. The cranial material consists in a right frontal and postorbital, both lacrimals, both maxilla and dentaries with in situ teeth, right surangular and prearticular. The postcranial remains consist of cervicals $3,5,6,7$ and 8 , dorsals 2 and 4, isolated ribs and gastralia, right humerus, manual ungual of digit III, left pubic shaft, left femur, and right tibia, astragalus, calcaneum, metatarsal III and pedal phalanges I-2, II-2, III-4 and IV-2. The length of the holotype has been estimated in ca. $5 \mathrm{~m}$.

A new specimen has been recently reported (MML220) from the same locality of the holotype (Paulina Carabajal et al. 2009). This specimen preserves bones not recorded in the holotype, consisting of a fragmentary maxilla, isolated teeth, posterior vertebrae, rib fragments, humerus, radius, ulna, one metacarpal (although the position of this element is not specific), four manual phalanges, two possible pedal phalanges, and metatarsals II-IV (it is not known if they are right or left elements).

Locality and horizon: Bajo de Santa Rosa, about $90 \mathrm{~km}$ southwest of Lamarque town, Río Negro Province, Argentina, in sediments of the Allen Formation (Campanian-Maastrichtian) (Fig. 1A). This formation is composed of continental sedimentary facies of mostly fluvial and lacustrine environments (Leanza et al. 2004). Among the dinosaur fauna recorded in this unit are titanosaurian sauropods (Salgado and Coria 1993, Salgado and Calvo 1999, Salgado and Azpilicueta 2000, J. Powell, unpublished data), and hadrosaurid and ankylosaurian ornithischians (Powell 1987, Salgado and Coria 1996). The theropod dinosaurs are represented by the abelisaurid Quilmesaurus curriei (Coria 2001, Juárez Valieri et al. 2007), a yet unnamed alvarezsaurid (Agnolín et al. 2006), and indeterminate tetanurans (Coria and Salgado 2005). 
Main anatomical features and comments: The discovery of Austroraptor provided access to a better knowledge of the South American dromaeosaurid morphological and paleobiological diversity. As discussed above, this theropod includes cranial remains, thus allowing comparisons with Buitreraptor. Moreover, this theropod is the biggest dromaeosaurid found in South America and shows morphological proportions that are unusual among dromaeosaurids, with very short forelimbs and osteological features that depart from the general pattern seen in dromaeosaurids.

The skull of Austroraptor (Fig. 2A, a-g) is extremely well elongated and low, being $25 \%$ longer than the femur, thus resembling the condition observed in Buitreraptor (Makovicky et al. 2005), with ca. $80 \mathrm{~cm}$ in length. The maxilla (Fig. 2A, a) is strongly elongated and low, with a very long anterior process. The antorbital fossa bears a single maxillary fenestra on its anteriormost end. The maxillary fenestra is elliptical and large, but is proportionally smaller than that in Buitreraptor. Additionaly, a wide bar divides the maxillary fenestra from the antorbital one, in contrast to the condition observed in Buitreraptor. The antorbital fenestra of Austroraptor is very large and elongated, being roughly triangular and with its anterior rim lower than the posterior one, thus differing from the more oval fenestra of Buitreraptor. The postantral wall of the antorbital fenestra is posteriorly extended, a feature not observed in Buitreraptor. Therefore, it cannot be considered a synapomorphy of Unenlagiinae, contra Novas et al. (2009). The ventral margin of the maxilla is straight and bears 24 teeth (Novas et al. 2009). The maxilla of Austroraptor sharply differs from that of Laurasian dromaeosaurids because in the latter the maxilla is dorsoventrally deeper, the anterior process anterior to the antorbital fossa is usually shorter, a promaxillary foramen anterior to the maxillary fenestra is present, the postantral wall is not posteriorly expanded, and the ventral margin is slightly convex. These derived features are present in Dromaeosaurus, Achillobator, Velociraptor, Tsaagan, Deinonychus, Atrociraptor, and Bambiraptor, among others (Colbert and Russel 1969, Ostrom 1969, Sues 1977, Currie 1995, Barsbold and Osmólska 1999, Perle et al. 1999, Burnham et al. 2000, Burnham 2004, Currie and Varricchio 2004, Norell et al. 2006,
Godefroit et al. 2008). The frontal of Austroraptor is sub-triangular in dorsal view (Fig. 2A, d), wider posteriorly and tapering anteriorly, as in troodontids (Currie 1987a, b, Makovicky and Norell 2004). Furthermore, it differs from that of most dromaeosaurids (e.g. Velociraptor, Tsaagan, Saurornitholestes, and Sinornithosau$r u s)$, in which the anterior end of the frontal is much less tapering and the anterior end is wider, bearing a more extensive contact with the nasal. The posterior portion of the frontal is marked by the supratemporal depression (Novas et al. 2009), which is anteriorly limited by a straight and oblique ridge, as occurs in Buitreraptor, instead of a sigmoid ridge as in most dromaeosaurids. Differing from other dromaeosaurids, the posterolateral process of the frontal of Austroraptor, which contacts the postorbitals, is not conical and is much less laterally projected in dorsal view (Fig. 2B, d, e).

The lacrimal (Fig. 2B, b, c) is quite different from the typical morphology observed in dromaeosaurids. Instead of being T-shaped, the jugal ramus is anteroposteriorly inclined. Moreover, this bone has a fossa situated at the posterodorsal corner of the antorbital fossa, where it is pierced by two foramina. Additionally, the posterior end of the dorsal ramus is laterally expanded into a triangular process that overhangs the orbit, a feature not previously recorded in other theropods (Novas et al. 2009). The postorbital is also unusual for dromaeosaurids, or even for unenlagiines, because in dromaeosaurids (including Buitreraptor) this bone is approximately triangular and trirradiate, whereas in Austroraptor it is dorsoventrally extended, with a ventral ramus with an acuminate and anteroventrally directed end.

The dentary is the only mandibular bone preserved (Fig. 2B, g), being extremely elongated, low, and straight. Its dorsal and ventral margins are parallel to each other in lateral view, while its posterior portion is slightly expanded dorsoventrally and ventrally directed. As in Buitreraptor and troodontids, a deep groove is situated on the lateral surface of the dentary, enclosing a row of nutrient foramina.

The teeth of Austroraptor bear a suite of characters only shared with the teeth of Buitreraptor (Gianechini et al. 2009). The tooth count of Austroraptor is large: the maxilla bears 24 teeth and the dentary 25 , resembling Buitreraptor that bears more than 20 alveoli 
in the dentary. The maxilla of Buitreraptor is broken, but it is very likely to have had a similar number of dental pieces. Other similarities between the two species are the total absence of mesial and distal carina and denticles, and the presence of grooves and ridges on the lateral sides of the teeth, which in this way take on a fluted appearance (Gianechini et al. 2009). On the other hand, the teeth of Austroraptor are conical and with circular crown basal section, thus differing from the teeth of Buitreraptor that are labiolingually compressed and eight-shaped in crown basal section.

The anterior cervical vertebrae (Fig. 2B, i, j) have low neural spines and a trapezoidal centrum in lateral view because the anterior surface forms an obtuse angle with respect to the ventral one. The ventral surfaces of these vertebrae are smooth and gently grooved, and longitudinal ridges form their lateral limits (Novas et al. 2009), as in Buitreraptor. The third cervical vertebra bears carotid processes on the anteroventral margin, as is also observed in the posterior cervicals of Buitreraptor, Microraptor, Tsaagan, troodontids and alvarezsaurids (Hwang et al. 2002, Makovicky and Norell 2004, Makovicky et al. 2005, Norell et al. 2006). The posterior cervicals (Fig. 2B, i, j) are anteroposteriorly shorter than those of Buitreraptor and devoid of neural spines and epipophyses, thus differing from Buitreraptor that has small epipophyses. However, the poor preservation of the cervicals of Austroraptor does not allow for confirming the absence of neural spines and epipophyses. The anterior dorsals are taller, with welldeveloped neural spines and anteroposteriorly shorter centra. The neural spines of these vertebrae are lower than the centrum and almost squared in lateral view. The dorsal end of these neural spines is transversely expanded into a spine table (Novas et al. 2009) (Fig. 2B, $\mathrm{k}, 1)$. Laurasian dromaeosaurids such as Deinonychus and Velociraptor (Ostrom 1969, Norell and Makovicky 1999) have also expanded spine tables, but not to the extent seen in Austroraptor. In contrast, Buitreraptor lacks spine tables on its dorsal vertebrae.

The short and robust humerus (Fig. 2B, h) of Austroraptor differs from the more slender and longer humerus of most dromaeosaurids. In the vast majority of dromaeosaurids like Deinonychus, the humerus represents $76 \%$ of the femoral length. In this regard, unen- lagiines present two extremes: on one hand, the humerus of Austroraptor is about $47 \%$ of the femoral length; on the other hand, in Buitreraptor, it represents approximately $93 \%$ of the femoral length (see table I). The deltopectoral crest is anteriorly projected and laterally flat, differing from that of Buitreraptor and Unenlagia, which have anterolaterally directed and laterally excavated deltopectoral crests (Novas et al. 2009). The shaft of the humerus is not bent as in Buitreraptor, but the distal portion is anteriorly curved. A manual ungual of digit III is present, which is small and strongly curved, even more than in other dromaeosaurids (Novas et al. 2009).

The femur (Fig. 2B, m) is robust, contrasting with the slender femur of Buitreraptor, and subequal in length with the tibia (approximately $99 \%$ of the tibial length). In some dromaeosaurids this proportion is slightly smaller, with a femoral length approximately greater or equal to $90 \%$ of the tibial length (see Table I), as seen in Buitreraptor, Velociraptor, Deinonychus, and Achillobator (Ostrom 1976c, Norell and Makovicky 1999, Perle et al. 1999, Makovicky et al. 2005, supplementary information, Novas et al. 2009). However, in other dromaeosaurids, this ratio is much smaller, as in Bambiraptor (70\%) and Microraptor (75\%) (Burnham 2004, $\mathrm{X}$. Xu, unpublished data) (see Table I). Along the posterior surface of the proximal part of the femur there is a strongly developed obturator ridge, also present in Sinornithosaurus and Sinovenator (X. Xu, unpublished data). Metatarsal III is long, representing $58 \%$ of the tibial length and about $59 \%$ of the femoral length, thus differing from the short metatarsus of Velociraptor, Deinonychus, and Dromaeosaurus (Colbert and Russel 1969, Ostrom 1969, Norell and Makovicky 1999). The pedal phalanx II-2 is similar to that of microraptorines, because it has a slightly longitudinally compressed shaft, poorly constricted between proximal and distal articular surfaces, a proximoventral heel triangular in dorsal and ventral views and poorly developed, and a distal ginglymoid articulation slightly expanded dorsoventrally, as in Sinornithosaurus, Microraptor, and Graciliraptor. Thus, the morphology of the pedal phalanx II-2 of Austroraptor resembles that of Troodontidae (X. $\mathrm{Xu}$, unpublished data). Phalanx IV-2 is unusually robust and twice as wide as phalanx II-2, thus being completely different from the one of other dromaeosaurids 
(e.g. Neuquenraptor, Buitreraptor, Deinonychus, and Velociraptor) (Ostrom 1969, Norell and Makovicky 1999, Makovicky et al. 2005, Novas and Pol 2005), in which the phalanx II-2 is slightly narrower than phalanx IV-2.

The new specimen of Austroraptor from the Bajo de Santa Rosa (MML-220), although incomplete, provides elements unrecorded in the holotype (Paulina Carabajal et al. 2009). From the presence of the radius it is possible to estimate the ratio between the forearm and the humerus. In this regard, the length of the forearm corresponds to approximately $75 \%$ of the length of the humerus, as is observed in Deinonychus (Paulina Carabajal et al. 2009), while in Bambiraptor, Sinornithosaurus, and Microraptor, this ratio is around $80 \%$ (Burnham 2004, X. Xu, unpublished data), and in Buitreraptor is $70 \%$ (Makovicky et al. 2005, supplementary information) (see Table I). The foot shows a subarctometatarsalian condition because of the fact that metatarsal III is proximally pinched and distally wide, covering metatarsals II and IV (metatarsal III is $25 \mathrm{~mm}$ in wide proximally and $49 \mathrm{~mm}$ distally) (Paulina Carabajal et al. 2009).

\section{COMPLEMENTARY EVIDENCE FROM ARGENTINA}

Additional information is represented by isolated teeth found at the Futalognko quarry, the same locality from where $U$. paynemili was recovered (Poblete and Calvo 2003). These teeth are characterized by a medium-size and strongly posteriorly inclined crown, labiolingual compression, absence of carina and denticles on the mesial border, and serrated distal border. The distal carina is lingually displaced and, consequently, the lingual side is less convex than the labial one. So, it can be said that these teeth occupy an anterior position in the mouth. These teeth also preserve the root, which exhibits welldeveloped lingual and labial depressions. They also bear a crest on the labial side of the root that extends sinuously to the apical portion of the crown, reaching the tip on the distal side. Some teeth bear small denticles on this apical crest (Poblete and Calvo 2003). Except for this latter character, which is unusual, the remaining features are observed in other dromaeosaurid teeth, as well as in other coelurosaurs such as alvarezsaurids and compsognathids, among others, and also in neovenatorids such as Orkoraptor (Novas et al. 2008, Ezcurra
2009, Benson et al. 2010). The presence of alvarezsaurids has been confirmed in the Portezuelo Formation (Novas 1996), so it is probable that some of these teeth belong to this group of theropods, although it is not possible to discard that they correspond to teeth of neovenatorids. Nevertheless, taking into account that the teeth of Buitreraptor and Austroraptor are completely devoid of denticles, it is little probable that the teeth from the Futalongko quarry belong to unenlagiines.

\section{FURTHER POSSIBLE EVIDENCES OF DROMAEOSAURIDS FROM OTHER SOUTH AMERICAN REGIONS}

Outside the Argentinean territory additional specimens and footprints have been reported, which have been attributed to deinonychosaur theropods. From deposits of the Bauru Group, specifically from the Marília and Adamantina formations, southern Brazil (Kellner and Campos 1999, 2000), several teeth have been collected and assigned to Dromaeosauridae and Troodontidae based on their morphology. The outcrops of the Adamantina Formation are situated in the São Paulo State and have been dated as Campanian-Maastrichtian in age (Bertini et al. 1993). The sediments of the Marília Formation, where additional material has been found in an outcrop at the Uberaba region, Minas Gerais State, are probably Maastrichtian in age (Bertini et al. 1993, Dias-Brito et al. 2001, Candeiro et al. 2004). The teeth recovered from these localities are generally small (with a height of 10 to $20 \mathrm{~mm}$ on average), labiolingually compressed, with mesial and distal carinae bearing denticles, or only present at the distal carina, or devoid of serrations on both borders. Although these teeth are considered as belonging to dromaeosaurids and troodontids (in this case the only record of troodontids for Gondwana), the morphology (especially the absence of serrated carinae) that they present can also be observed in other maniraptorans, such as alvarezsaurids and ornithomimosaurs (e.g., Pelecanymimus polyodon, Pérez-Moreno et al. 1994), or even in other coelurosaurians (e.g., Compsognathidae), and basal tetanurae (e.g., Orkoraptor). However, as explained above, South American dromaeosaurids as Buitreraptor certainly show teeth of this kind. Additional teeth considered as likely deinonychosaurians come from the Alcântara Formation (Albian-Cenomanian), São Luís-Grajaú Basin, North-Northeastern Brazil, a geological unit in which, as in the precedent quarry of 
Buitreraptor (De Valais and Apesteguía 2001), teeth attributable to other theropod groups, such as Carcharodontosauridae (Elias et al. 2004, 2005, 2006), were also found.

Additionally, skeletal remains are also described from the Bauru Group, specifically an ungual phalanx (Novas et al. 2005) and a scapula (Machado et al. 2008). These remains have been tentatively assigned to nonavian maniraptoran, mainly based on general characters seen in this group of theropods. However, the exact taxonomic affiliation of these isolated elements is difficult to establish. In the case of the scapula, comparisons with other theropods are limited (Machado et al. 2008), but based on a twisted acromial part and the overall shape of the glenoid, the relation with Maniraptora is possible. On the other hand, although the ungual phalanx has common characters with ungual phalanges of other non-avian maniraptoran, it has unique anatomical features that suggest that it belongs to a clade of derived maniraptoran unknown in South America (Novas et al. 2005).

Further remains also consisting of teeth come from the Upper Magdalena Basin, Girardot Sub-basin (Maastrichtian), Department of Tolima, central-western Colombia (Ezcurra 2009). In this locality a single coelurosaurian tooth was found (UCMP 39649b) with a morphology resembling that of dromaeosaurid teeth. This tooth is small, distally curved, labiolingually compressed, and devoid of serrated mesial and distal carinae, and also without any constriction at the base of the crown. This last feature is the main difference from other taxa that possess teeth devoid of serrations, such as ornothomimosaurs, alvarezsaurids, basal oviraptorosaurs, some troodontids, and some avialans (Ezcurra 2009). The cited characters have been already observed in teeth of unenlagiine dromaeosaurids. However, the lateral grooves of the crown observed in Buitreraptor and Austroraptor (Makovicky et al. 2005, Novas et al. 2009, Gianechini et al. 2009) are not present in the Colombian tooth, although it should be noted that some teeth of Buitreraptor are devoid of grooves. On the other hand, UCMP $39649 \mathrm{~b}$ does not possess the eight-shaped crown basal section present in Buitreraptor or either the conical crown observed in Austroraptor. But taking into account that the teeth of Buitreraptor and Austroraptor are not identical, although they share morphological features it is possible to say that UCMP $39649 \mathrm{~b}$ belongs to an unenlagiine tooth, considering its common characters with the unenlagiine dentition. Accordingly, the assignment of the Colombian tooth to Unenlagiinae, although likely, remains so far only an attempt (Ezcurra 2009).

Nevertheless, as the tooth record is ambiguous, and because of the large amount of morphological homoplasy associated with these anatomical structures, the presence of deinonychosaurs in Brazil and Colombia will only be confirmed after the discovery of skeletal materials unquestionably referable to this group of theropods.

Additional evidence of the possible presence of deinonychosaurs in South America is found at the Toro Toro National Park, Bolivia, where outcrops of limestone from the Lower Member of the El Molino Formation (middle Maastrichtian) reveal well-preserved sauropod, theropod, and ornithischian dinosaur trackways (S. Apesteguía et al., unpublished data). Some of these trackways are characterized by a peculiar morphology where the footprint of the inner toe is reduced in length and bears a distal bump or even some without inner toe impression. These tracks have an average length of $22 \mathrm{~cm}$, and an average width of $15.9 \mathrm{~cm}$, with digit III being the longest and having a larger claw than digit IV. This indicates possible functional didactility of the theropod that left the footprints, a defining feature of deinonychosaurs, which had kept its specialized pedal digit II high ground when marching (S. Apesteguía et al., unpublished data). Moreover, the print of digit II only preserves the first phalanx, thus differing from the known skeletal reconstructions that show the inner toe completely above ground (S. Apesteguía et al. unpublished data). Although consisting only of footprints, this record implies the presence of other deinonychosaurian taxa in places of South America where there was no previous record of these theropods. Considering the size that would have reached such animals, the footprints of Toro Toro match very well with large unenlagiines like Austroraptor.

\section{DISCUSSION AND CONCLUSIONS}

The record of dromaeosaurids in South America is still poor compared with that of North America and Asia, taking into account the less number of taxa and the gen- 
erally fragmentary nature of the specimens. Nevertheless, the recent discoveries in Argentina, mainly of Buitreraptor and Austroraptor, have provided much information about the anatomy and phylogenetic relationships of this group of South American theropods. Although the record of South American dromaeosaurids it not yet as elocuent as that of North America, they have many distinctive characters that can be considered as endemic features and could be the result of vicariant evolution (Makovicky et al. 2005, Novas and Pol 2005, J.F. Bonaparte, unpublished data).

Unenlagia comahuensis was considered as bearing avian features, especially in the pelvic girdle (Novas and Puerta 1997, Novas 2004). Many anatomical similarities with pelvic bones of Archaeopteryx, Confuciusornis, and other early birds, show that a close relationship between these taxa and Unenlagia may be present. On the other hand, similarities between the scapular girdles are more difficult to see due to the absence of coracoid in Unenlagia. Considering the anatomical features of the scapula and the location of the glenoid, the general similarity among the scapulae of Archeopteryx, Buitreraptor and Unenlagia, mainly their twisted shaft, leads to a possible lateral faced glenoid in Unenlagia.

The anatomy of Unenlagia paynemili has some apomorphies in common with $U$. comahuensis (Calvo et al. 2004), but also some differences. The first difference is the smaller and more slender bones of $U$. paynemili. The humerus of the two taxa differs mainly in terms of size. The angle of contact between the deltopectoral crest and the shaft (doubtful), and the presence/absence of a ridge on the dorsal margin posterior to the deltopectoral crest (Fig. 4A), are ambiguous differences due to the poor preservation of the deltopectoral crest. The discrepancies observed in the pelvic girdle are greater than those found before (Fig. 4B, C), and some characters, like the presence of a supratrochanteric process and an inflection of the posterodorsal rim of the ilium, are more widespread, and although characteristic of Unenlagia, they are not exclusively. Moreover, the variation observed in the brevis fossa must be considered between the holotype of and the referred specimen of Buitreraptor, which shows that little morphological differences can appear among individuals of the same species. On the other hand, it is likely that differences in size, proportions and angles could be the result of ontogenetic changes, or even sexual dimorphism or intrapopulation variation. Accordingly, a possible synonymy is considered, but the differences presented between $U$. comahuensis and $U$. paynemili are significant enough to consider both taxa as separate species, at least until new materials provide new anatomical data that allow more detailed comparisons.

Neuquenraptor shows similarities with both species of Unenlagia. Due to the very poor state of preservation of the femur of Neuquenraptor, comparisons between both skeletal elements must be taken cautiously. In the autopodium, the pedal phalanges II-1 of Neuquenraptor and U. paynemili are strikingly similar to each other (Fig. 5B), as previously noted by Makovicky et al. (2005, supplementary information). On the other hand, phalanx II-2 of $U$. paynemili is shorter than that of Neuquenraptor, but, leaving aside the length, the morphology of this phalanx in both taxa is very similar. However, it should be noted that phalanges II- 1 and II-2 were not found in association with the holotype of $U$. paynemili. Therefore, these phalanges could not be assigned to this species (Novas 2009). Taking into account this matter, the synonymy between Unenlagia and Neuquenraptor proposed by Makovicky et al. (2005) is not possible to ensure, and more materials from the Portezuelo Formation are necessary to solve this question. In Buitreraptor and Rahonavis, phalanx II-1 is larger than phalanx II-2, like in U. paynemili. Therefore, the similar length of the phalanges of digit II of Neuquenraptor is significant, but this distinction alone is not enough evidence to reject the hypothesis of synonymy. Unfortunately, the remaining bones preserved in $U$. comahuensis and U. paynemili are not present in Neuquenraptor, and the pedal bones present in Neuquenraptor were not preserved in the former species; thus, additional comparisons between them are not possible. Accordingly, with the anatomical knowledge currently at hand from these taxa, it is not possible to support or reject a synonymy between Unenlagia and Neuquenraptor.

Many similar features are present in the morphology of the metatarsus of unenlagiines (Fig. 2B, k, 1, and $5 \mathrm{~A}, \mathrm{~g}-\mathrm{i})$ and microraptorines, and also with troodontids. The three groups share a relatively long and slender metatarsus, a moderately developed distal ginglymus of metatarsal III, a subarctometatarsian condition 
with metatarsal III wedged between metatarsals II and IV, the distal part of metatarsal III covering the anterior surfaces of metatarsals II and IV, and metatarsals II and IV almost of the same length (Xu et al. 1999, $\mathrm{Xu}$ and Wang 2000, Xu et al. 2000, Hwang et al. 2002, Makovicky et al. 2005, Novas and Pol 2005, X. Xu, unpublished data). Moreover, Sinornithosaurus (a microraptorine) shares with Buitreraptor a ball-like distal articulation of metatarsal I, and a moderately developed distal ginglymus of metatarsal II (Xu et al. 1999, Xu and Wang 2000). On the other hand, some similarities are observed between the pedal digits II of these groups. Phalanx II-2 in Neuquenraptor and Buitreraptor is relatively longer, has a proximoventral heel, a constriction at midpoint of the shaft, and a distal articulation less developed than Laurasian dromaeosaurids, as also observed in microraptorines and troodontids. By contrast, phalanx II-2 of $U$. paynemili is more similar to that of Laurasian dromaeosaurids. However, a difference is noted between the lengths of phalanges II- 1 and II-2 because unenlagiines have a phalanx II-1 slightly longer than phalanx II-2, thus resembling the proportions of troodontids, but differing from that of microraptorines (Xu et al. 1999, Xu and Wang 2000). An exception to these anatomical features is represented by the metatarsus of Rahonavis, which is shorter, without a proximal pinched metatarsal III, and without a posterolateral flange of metatarsal IV (Forster et al. 1998), thus resembling the metatarsus of Laurasian dromaeosaurids. However, characters that are commnon in the metatarsus (subarctometatarsal condition and longitudinal flange along posterolateral surface of metatarsal IV) and pedal phalanges of unenlagiines, microraptorines, and troodontids can be considered as synapomorphies of Deinonychosauria (Makovicky et al. 2005, supplementary information). The metatarsal morphology of derived dromaeosaurids (i.e. Velociraptorinae and Dromaeosaurinae), can be considered as a reversion (Xu and Wang 2000), but Turner et al. (2007, supplementary information) and Novas et al. (2009, supplementary information) interpreted these metatarsal features as synapomorphic of the clade Microraptorinae + Unenlagiinae, and the laterally directed flange of metatarsal IV of Velociraptor mongoliensis as a parallelism. Another feature to be considered as a possible synapomorphy of Microraptorinae + Unenlagiinae is the great length of the metatarsus, corresponding to $50 \%$ or more of the length of the femur (character 312 of $\mathrm{Hu}$ et al. 2009) (see Table I).

Austroraptor shows many characters not previously recorded in dromaeosaurids, mainly referred to the cranial and pedal anatomy, and to the forelimb/hindlimb proportion (Novas et al. 2009). The bones of the skull that are most distinctive with respect to those of other dromaeosaurids are the maxilla, the lacrimal, and the postorbital (Fig. 2A, a, b, c, f). The humerus is extremely short in comparison with that of dromaeosaurids (Fig. 2A, h), showing an unusually low humerus/ femur ratio. Additionally, phalanx IV-2 is more robust than observed in other dromaeosaurids. All these characters distinguish Austroraptor from the Laurasian dromaeosaurid lineage. On the other hand, some features are shared with Buitreraptor especially in the maxilla, dentary, and teeth (Gianechini et al. 2009, Novas et al. 2009). However, as stated before, Buitreraptor has characters not observed in Austroraptor, such as a larger maxillary fenestra (in Austroraptor it is large but comparable to other dromaeosaurids), a narrower interfenestral bar, frontals not abruptly tapering anteriorly (like Laurasian dromaeosaurids), a triangular postorbital (more similar to that of Laurasian dromaeosaurids), teeth more compressed and with an eight-shaped basal section of the crown, neural spines of the dorsal vertebrae without distal spine tables, longer humerus, and femur devoid of obturator ridge. Due to the absence of spine tables in the dorsal vertebrae of Buitreraptor, this character cannot be taken as a synapomorphy of Unenlagiinae, contra Novas et al. (2009).

In sum, despite of the unique characters of these two theropods, it is possible to say that Buitreraptor has more dromaeosaurid features than Austroraptor. However, it is also true that Buitreraptor is earlier in age and, considering a vicariant evolution, because of it being closer in morphological disparity to Laurasian species. Conversely, Austroraptor is Maastrichtian in age, with a greater period of time from the geographical separation of northern and southern dromaeosaurids.

The putative deinonychosaur remains from Brazil, Colombia, and Bolivia, although inconclusive, provide evidence for the presence of this clade out of Argentina, which would be expected since no geographical barriers confined it to inhabit the whole territory. It 
probably achieved a continental distribution, as has been raised previously by diverse authors (e.g. Makovicky et al. 2005, Novas and Pol 2005, Ezcurra 2009).

\section{ACKNOWLEDGMENTS}

The authors wish to thank Carlos Muñoz, from the Museo Carlos Ameghino, Cipolletti, Río Negro, for allowing the study of the material of Buitreraptor; to Fernando E. Novas for granting access to material of Austroraptor and allowing the photographs of the materials. We are also grateful to Peter Makovicky for having provided photographs of many of the materials compared here; to Juan Porfiri for responding so kindly to some queries raised about the specimens, and Jorge Calvo for allowing the study of the materials of Unenlagia paynemili. Special thanks are also given to Manuel Medeiros, Elaine Machado and Carlos Candeiro for providing information about the record of theropods in Brazil. Thanks to Gabriel Lio for his artwork. Special thanks to Federico Agnolín and Pablo Chiarelli for their very useful critical comments, and reviewers for their significant contributions, which helped to improve the quality of this work. We are also thankful to The Jurassic Foundation, which supported the visit to the respective collections.

\section{RESUMO}

Nas últimas duas décadas, o registro do dromaeossaurídeos Unenlagiinae da América do Sul aumentou substancialmente tanto em quantidade, assim como na qualidade dos espécimes. Uma revisão sumária do registro sul americano para estes terópodos é apresentada aqui. Unenlagia comahuensis, Unenlagia paynemili e Neuquenraptor argentinus provenientes da Formação Portezuelo, sendo o primeiro o mais completo e com características avianas putativas. Neuquenraptor, muito incompleto, demonstra as características do pé que assemelhamse àquelas de Unenlagia. O mais velho, e mais completo dromaeossaurídeo americano é Buitreraptor gonzalezorum, cujo possui preservado ossos cranianos, fornece implicações importantes na caracterização dos unenlagiines. Descrito recentemente, Austroraptor cabazai, também com ossos cranianos, permite mais comparações com linhagens provenientes da Laurasia e uma melhor caracterização dos unenlagiineos. A possível sinonímia entre Unenlagia e Neuquenraptor é discutido. As evidências adicionais do Brasil e da Colômbia mostram que dinossauros com dentição semlhante à dos unenlagiineos eram representados em toda América do Sul; entretanto, estas evidências podem igualmente ser relacionadas a outros maniraptores desconhecidos, considerando a grande diversidade do grupo na América do Sul.

Palavras-chave: Deinonychosauria, Dromaeosauridae, América do Sul, Unenlagiinae.

\section{REFERENCES}

Agnolin FL, Novas FE And Powell JE. 2006. New alvarezsaurid theropod from the Latest Cretaceous of Río Negro province, Patagonia, Argentina. XXII Jornadas Argentinas de Paleontología de Vertebrados (Abstracts Book): 1 .

Allain R And Taquet P. 2000. A new genus of Dromaeosauridae (Dinosauria, Theropoda) from the Upper Cretaceous of France. J Vert Paleont 20: 404-407.

Apesteguía S And Novas FE. 2003. Large Cretaceous sphenodontian from Patagonia provides insight into lepidosaur evolution in Gondwana. Nature 425: 609-612.

Apesteguía S AND ZAher H. 2006. A Cretaceous terrestrial snake with robust hindlimbs and a sacrum. Nature 440: 1037-1040.

BARsBold R. 1983. Carnivorous dinosaurs from the Cretaceous of Mongolia. Trudy Sovm Sov-Mong Paleontol Eksped 24: 1-117. (In Russian with English summary)

BARSBOLD R AND OSMÓLSKA H. 1999. The skull of Velociraptor (Theropoda) from the Late Cretaceous of Mongolia. Acta Palaeontol Pol 44: 189-219.

BARsbold R, Osmólska H, WATABE M, CURrie PJ AND TSOgtBaAtAR K. 2000. A new oviraptorosaur (Dinosauria, Theropoda) from Mongolia: the first dinosaur with a pygostyle. Acta Palaeontol Pol 45(2): 97-106.

Benson RBJ, CARrano MT and Brusatte SL. 2010. A new clade of archaic large-bodied predatory dinosaurs (Theropoda: Allosauroidea) that survived to the latest Mesozoic. Naturwissenschaften 97: 71-78.

Bertini RJ, Marshall LG, Gayet M And Brito PM. 1993. Vertebrate faunas form the Adamantina and Marilia Formations (upper Baurú Group, Upper Cretaceous, Brazil) in their stratigraphic and paleobiogeographic context. Neues Jahrb Geol Paläont Abh 188: 72-101.

BonAPARTE JF. 1999. Tetrapod faunas from South America and India: a paleobiogeographic interpretation. Proc Indian Nat Sci Acad 65: 427-437.

BRissón EgLi F AND APESTEguía S. 2008. Noasaurid remains from the Candeleros Formation at "La Buitrera" (early Upper Cretaceous) Río Negro, Argentina. III Congreso Latinoamericano de Paleontología de Vertebrados, Libro de Resúmenes 31. 
BURNHAM DA. 2004. New information on Bambiraptor feinbergi (Theropoda: Dromaeosauridae) from the Late Cretaceous of Montana. In: CURRIE PJ ET AL. (Eds), Feathered Dinosaurs, Bloomington: Indiana University Press, p. 67-111.

Burnham DA, Derstler KL, CURrie PJ, BAKKer RT, ZHoU Z AND OSTRom JH. 2000. Remarkable new birdlike dinosaur (Theropoda: Maniraptora) from the Upper Cretaceous of Montana. Univ Kansas Paleont Contrib 13: $1-14$.

Calvo JO, Porfiri JD And Kellner AWA. 2004. On a new maniraptoran dinosaur (Theropoda) from the Upper Cretaceous of Neuquén, Patagonia, Argentina. Arq Mus Nac Rio Jan 62: 549-566.

Calvo JO And Salgado L. 1995. Rebbachisaurus tessonei sp. nov., a new Sauropoda from the Albian-Cenomanian of Argentina: new evidence on the origin of the Diplodocidae. Nat Sci Mus Monogr 15: 13-45.

CANDeiro CRA, Bergqvist LP, Novas FE ANd CurRIE PJ. 2004. Theropod teeth from the Marilia Formation (Upper Maastrichtian), Minas Gerais State, Brazil. In: Annual Meeting Society of Vertebrate Paleontology, Denver Museum of Nature and Science and the University of Colorado Museum, Denver and Colorado, $204 \mathrm{p}$.

Carignano AP, Pol D, Apesteguía S and Novas FE. 2002. La diversidad de cocodrilos de 'La Buitrera' (Fm. Candeleros), provincia de Río Negro. Ameghiniana 39(Supl): 7R.

CARPENTER K. 2002. Forelimb biomechanics of nonavian theropod dinosaurs in predation. Senckenbergiana Lethaea 82: 59-76.

Chiappe LM, Shu'an J, Qiang J And Norell MA. 1999. Anatomy and systematics of the Confuciusornithidae (Theropoda: Aves) from the Late Mesozoic of Northeastern China. Bull Am Mus Nat Hist 242: 1-89.

ClARKE JA. 2004. Morphology, phylogenetic taxonomy, and systematics of Ichthyornis and Apatornis (Avialae: Ornithurae). Bull Amer Mus Nat Hist 286: 1-179.

Colbert EH AND Russel DA. 1969. The small cretaceous dinosaur Dromaeosaurus. Amer Mus Novitates 2380: 149.

CORIA RA. 2001. New theropod from the Late Cretaceous of Patagonia. In: TANKE DH AND CARPENTER K (Eds), Mesozoic Vertebrate Life, Bloomington \& Indianapolis: Indiana University Press, p. 3-9.

Coria RA, Currie PJ, Eberth D, Garrido A AND KoppelHus E. 2001. Nuevos vertebrados fósiles del Cretácico Superior de Neuquén. Ameghiniana 38(Supl): 6R.
CORIA RA AND SAlgado L. 1995. A new giant carnivorous dinosaur from the Cretaceous of Patagonia. Nature 377: 224-226.

Coria RA AND SAlgado L. 2005. Latest Patagonian nonavian theropods. In: CARPENTER K (Ed), The Carnivorous Dinosaurs, Bloomington: Indiana University Press, p. $153-160$.

CURRIE PJ. 1987a. Theropods of the Judith River Formation of Dinosaur Provincial Park, Alberta, Canada. In: Currie PJ AND Koster EH (Eds), Fourth Symposium on Mesozoic Terrestrial Ecosystems, Drumheller, Alberta: Tyrrel Museum of Paleontology, p. 52-60.

CURRIE PJ. 1987b. Bird-like characteristics of the jaws and teeth of troodontid theropod (Dinosauria, Saurischia). J Vert Paleont 7: 72-81.

CURRIE PJ. 1995. New information of the anatomy and relationships of Dromaeosaurus albertensis (Dinosauria : Theropoda). J Vert Paleont 15: 576-591.

CURrie PJ AND Dong Z. 2001. New information on Cretaceous troodontids (Dinosauria, Theropoda) from the People's Republic of China. Can J Earth Sci 38: 1753-1766.

CURrie PJ AND VARricchio DJ. 2004. A new dromaeosaurid from the Horseshoe Canyon Formation (Upper Cretaceous) of Alberta, Canada. In: CURRIE PJ ET AL. (Eds), Feathered Dragons: Studies from the transition from dinosaurs to birds, Bloomington: Indiana University Press, p. 113-132.

CURrie PJ, RIgBY JR JK AND SLOAN RE. 1990. Theropod teeth from the Judith River Formation of southern Alberta, Canada. In: CARPENTER K AND CURRIE PJ (Eds), Dinosaur Systematics: Perspectives and Approaches, Cambridge: Cambridge University Press, p. 107-125.

De Valais S And Apesteguía S. 2001. Dientes asignables a Giganotosaurus (Carcharodontosauria, Theropoda) provenientes de "La Buitrera", Fm. Candeleros, Provincia de Río Negro. Ameghiniana 38(Supl): 6R.

Dias-Brito D, Musacchio EA, Castro JC, MaraNHÃo MSAS, SUÁREZ JM AND Rodrigues R. 2001. Grupo Bauru: uma unidade continental do Cretáceo no Brasil - concepções baseadas em dados micropaleontológicos, isotópicos e estratigráficos. Rev Paleobiol 20: 245304.

Elias FE, Bertini RJ And Medeiros MA. 2004. Nota preliminar sobre novos morfótipos de dentes tetrapodianos, coletados na Laje do Coringa, Formação Alcântara, eo-Cenomaniano do norte do Estado do Maranhão. IV Simpósio Brasileiro de Paleontologia de Vertebrados (Abstracts Book): 21-22. 
Elias FE, Bertini RJ AND Medeiros MA. 2005. Review of the occurrences concerning isolated amniotes teeth, in the Cretaceous deposits from the Maranhão State. II Congreso Latino-Americano de Paleontologia de Vertebrados (Abstracts Book): 99-100.

Elias FE, Bertini RJ And Medeiros MA. 2006. A diversidade de amniotas do afloramento "Laje do Coringa", Formação Alcântara, eo-Cenomaniano do Estado do Maranhão. Inferências com base em registro dentário. $7^{\circ} \mathrm{Sim}$ pósio do Cretáceo do Brasil, $1^{\circ}$ Simpósio do Terciário do Brasil (Abstracts Book): 46.

ELZANOWSKI A. 2002. Archaeopterygidae (Upper Jurassic of Germany). In: ChiAppe LM AND WitMer LM (Eds), Mesozoic birds: Above the head of dinosaurs, Berkeley, Los Angeles and London: University of California Press, p. 129-159.

EzCURRA MD. 2009. Theropod remains from the uppermost Cretaceous of Colombia and their implications for the palaeozoogeography of western Gondwana. Cretac Res 30: 1339-1344.

Forster CA, SAmpson SD, ChiAppe LM AND KraUse DW. 1998. The theropod ancestry of birds: new evidence from the Late Cretaceous of Madagascar. Science 279: 1915-1919.

Gallina PA And Apesteguía S. 2005. Cathartesaura anaerobica gen. et sp. nov., a new rebbachisaurid (Dinosauria, Sauropoda) from the Huincul Formation (Upper Cretaceous), Río Negro, Argentina. Rev Mus Arg Cs Nat, n s 7: $153-166$.

GAUTHIER J. 1986. Saurischian monophyly and the origin of birds. In: PADIAN K (Ed), The Origin of Birds and the Evolution of Flight. Mem California Acad Sci 8: 1-55.

Gianechini FA, Apesteguía S And Makovicky PJ. 2009. The unusual dentiton of Buitreraptor gonzalezorum (Theropoda : Dromaeosauridae), from Patagonia, Argentina: new insights on the unenlagine teeth. Ameghiniana 46(Supl): 29R.

Godefroit P, Currie PJ, Hong L, Yong SC And Ming DZ. 2008. A new species of Velociraptor (Dinosauria: Dromaeosauridae) from the Upper Cretaceous of northern China. J Vert Paleont 28: 432-438.

HEADDEN J. 2008. "Stork raptor" in Deviantart.com (http://browse.deviantart.com/?q=buitreraptor\&order $=9$ \&offset $=48 \# / \mathrm{d} 1 \mathrm{ha} 7 \mathrm{nb}$ )

Holtz JR. TR 2004. Tyrannosauroidea. In: WEISHAMPEL DB ET AL. (Eds), The Dinosauria, Berkeley, Los Angeles and London: University of California Press, p. 111-136.

Hu D, Hou L, Zhang L AND XU X. 2009. A pre-Archaeo- pteryx troodontid theropod from China with long feathers on the metatarsus. Nature 461: 640-643.

HutChinson JR. 2001. The evolution of femoral osteology and soft tissues on the line to extant birds (Neornithes). Zool J Linnean Soc 131: 169-197.

HWANG SH. 2005. Phylogenetic patterns of enamel microstructure in dinosaur teeth. J Morph 266: 208-240.

Hwang SH, Norell MA, Qiang J AND Keqin G. 2002. New specimens of Microraptor zhaoianus (Theropoda: Dromaeosauridae) from Northeastern China. Amer Mus Novitates 3381: 1-44.

JuÁrez VAlieri R, Fiorelli L and Cruz L. 2007. Quilmesaurus curriei Coria, 2001 (Dinosaurio, Theropoda). $\mathrm{Su}$ validez taxonómica y relaciones filogenéticos. Rev Mus Arg Cs Nat 9: 59-66.

Kellner AWA and CAmpos DA. 1999. Vertebrate paleontology in Brazil - a review. Episodes 22(3): 238-251.

Kellner AWA AND CAmpos DA. 2000. Brief review of dinosaur studies and perspectives in Brazil. An Acad Bras Cienc 72: 509-538.

Kirkland Ji, Gaston R And Burge D. 1993. A large dromaeosaur (Theropoda) from the Lower Cretaceous of Eastern Utah. Hunteria 2: 1-16.

KURZANOV SM. 1981. An unusual theropod from the Upper Cretaceous of Mongolia. Fossil Vertebrates of Mongolia, Joint Soviet-Mongolian Paleontological Expedition (in russian) 15: 39-49.

Leanza HA, Apesteguía S, Novas FE AND DE LA FUENTE MS. 2004. Cretaceous terrestrial beds from the Neuquén Basin (Argentina) and their tetrapod assemblages. Cretac Res 25: 61-87.

LONGRICH NR AND CURRIE PJ. 2009. A microraptorine (Dinosauria-Dromaeosauridae) from the Late Cretaceous of North America. Proc Nat Acad Sci 106: 5002-5007.

LÜ J-C, Xu L, Zhang X-L, Ji Q, Jia S-H, Hu W-Y, ZHANG J-M AND WU Y-H. 2007. New dromaeosaurid dinosaur from the Late Cretaceous of Qiupa Formation of Luanchuan area, western Henan, China. Geol Bull China 26: 777-786.

Machado EB, De Almeida Campos D and Kellner AWA. 2008. On a theropod scapula (Upper Cretaceous) from the Marília Formation, Bauru Group, Brazil. Paläeontol Z 82: 308-313.

Makovicky PJ, Apesteguía S And Agnolín FL. 2005. The earliest dromaeosaurid theropod from South America. Nature 437: 1007-1011.

Makovicky PJ, Kobayashi Y AND CURRIE PJ. 2004. Ornithomimosauria. In: WEISHAMPEL DB ET AL. 
(Eds), The Dinosauria, Berkeley, Los Angeles and London: University of California Press, p. 137-150.

Makovicky PJ AND Norell MA. 2004. Troodontidae. In: Weishampel DB et AL. (Eds), The Dinosauria, Berkeley, Los Angeles and London: University of California Press, p. 184-195.

Makovicky PJ, Norell MA, Clark JM and Rowe T. 2003. Osteology and relationships of Byronosaurus jaffei (Theropoda: Troodontidae). Amer Mus Novitates 3402: $1-32$.

Matthew WD And Brown B. 1922. The family Deinodontidae, with a notice of a new genus from the Cretaceous of Alberta. Bull Amer Mus Nat Hist 46: 367-385.

Norell MA, Clark JM, Turner AH, Makovicky PJ, BARSBOLD R AND Rowe T. 2006. A new dromaeosaurid theropod from Ukhaa Tolgod (Ömnögov, Mongolia). Amer Mus Novitates 3545: 1-55.

Norell MA AND MAKOVICKY PJ. 1997. Important features of the dromaeosaur skeleton: information from a new specimen. Amer Mus Novitates 3215: 1-28.

Norell MA AND MAKOVICKY PJ. 1999. Important features of the dromaeosaurid skeleton II: information from newly collected specimens of Velociraptor mongoliensis. Amer Mus Novitates 3282: 1-45.

Norell MA AND MaKovicky PJ. 2004. Dromaeosauridae. In: Weishampel DB ET AL. (Eds), The Dinosauria, Berkeley, Los Angeles and London: University of California Press, p. 196-209.

Norell MA, Makovicky PJ, Bever GS, Balanoff AM, Clark JM, BARSBOLd R AND Rowe T. 2009. A Review of the Mongolian Cretaceous Dinosaur Saurornithoides (Troodontidae: Theropoda). Amer Mus Novitates 3654: 1-63.

Norell MA, Makovicky PJ AND Clark JM. 2000. A new troodontid theropod from Ukhaa Tolgod, Mongolia. J Vert Paleontol 20: 7-11

Novas FE. 1996. Alvarezsauridae, Cretaceous basal birds from Patagonia and Mongolia. Mem Queens Mus 39: 675-702.

Novas FE. 1997. Anatomy of Patagonykus puertai (Theropoda, Avialae, Alvarezsauridae), from the Late Cretaceous of Patagonia. J Vert Paleontol 17: 137-166.

Novas FE. 1998. Megaraptor namunhuaiquii, a largeclawed, Late Cretaceous theropod from Patagonia. J Vert Paleont 18: 4-9.

NovAs FE. 2004. Avian traits in the ilium of Unenlagia comahuensis (Maniraptora, Avialae). In: CURRIE PJ ET AL. (Eds), Feathered Dragons: Studies from the transi- tion from dinosaurs to birds, Bloomington: Indiana University Press, p. 150-166.

Novas FE. 2009. The age of dinosaurs in South America, Bloomington: Indiana University Press, $480 \mathrm{p}$.

Novas FE, Borges Ribeiro LC AND Souza CARvalho I DE. 2005. Maniraptoran theropod ungual from the Marília Formation (Upper Cretaceous), Brazil. Rev Mus Arg Cs Nat n s 7: 31-36.

Novas FE, EzcurRa MD And LecuOna A. 2008. Orkoraptor burkei nov. gen. et sp., a large theropod from the Maastrichtian Pari Aike Formation, Southern Patagonia, Argentina. Cretac Res 29: 468-480.

Novas FE AND Pol D. 2005. New evidence on deinonychosaurian dinosaurs from the Late Cretaceous of Patagonia. Nature 433: 858-861.

Novas Fe, Pol D, Canale Ji, Porfiri JD and Calvo JO. 2009. A bizarre Cretaceous theropod dinosaur from Patagonia and the evolution of Gondwanan dromaeosaurids. Proc Roy Soc B 276: 1101-1107.

Novas FE ANd PUERTA PF. 1997. New evidence concerning avian origins from the Late Cretaceous of Patagonia. Nature 387: 390-392.

OSBORN HF. 1924. Three new Theropoda, Protoceratops zone, central Mongolia. Amer Mus Novitates 144: 1-12.

Osmólska H, Roniewicz E ANd Barsbold R. 1972. A new dinosaur, Gallimimus bullatus n. gen., n. sp. (Ornithomimidae) from the Upper Cretaceous of Mongolia. Results of the Polish-Mongolian palaeontological expeditions. Palaeont Pol 27: 103-143.

Ostrom JH. 1969. Osteology of Deinonychus antirrhopus, an unusual theropod from the Lower Cretaceous of Montana. Bull Peabody Mus Nat Hist 30: 1-165.

Ostrom JH. 1974. The pectoral girdle and forelimb function of Deinonychus (Reptilia: Saurischia): a correction. Postilla, Peabody Museum, Yale University 165: 1-11.

Ostrom JH. 1975. On the origin of Archaeopteryx and the ancestry of birds. Problèmes Actuels de PaléontologieÉvolution des Vertébrés. Colloque International CNRS 218: 519-532.

Ostrom JH. 1976a. Some hypothetical anatomical stages in the evolution of avian flight. In: OLSON SL (Ed), Collected Papers in Avian Paleontology, Honoring the 90th Birthday of Alexander Wetmore, p. 1-21.

Ostrom JH. 1976b. Archaeopteryx and the origin of birds. Biol J Linnean Soc 8: 91-182.

Ostrom JH. 1976c. On a new specimen of the Lower Cretaceous theropod dinosaur Deinonychus antirrhopus. Breviora 439: 1-21. 
Ostrom JH. 1986. The cursorial origin of avian flight. In: PADIAN K (Ed), The Origin of Birds and the Evolution of Flight, California Academy of Sciences, Memoirs of the California Academy of Sciences 8: 73-81.

PAUL GS. 2002. Dinosaurs of the air. The evolution and loss of flight in dinosaurs and birds, Baltimore and London: The John Hopkins University Press, 460 p.

Paulina Carabajal A, Currie PJ, García R, Salgado L, Cerda i, Fernández MS, Reichel M, Sissons R, Koppelhus E ANd CABAZA D. 2009. Un nuevo especimen de Austroraptor (Dinosauria: Theropoda: Dromaeosauridae) del Cretácico Tardío (Maastrichtiano) de Río Negro, Argentina. Ameghiniana 46(Supl): $41 \mathrm{R}$.

PÉrez-Moreno BP, Sanz JL, Buscalioni AD, MoRATAlla JJ, ORTEGA F AND RASSKIN-GutMan D. 1994. A unique multitoothed ornithomimosaur from the Lower Cretaceous of Spain. Nature 370: 363-367.

Perle A, Chiappe LM, Barsbold R, Clark JM AND Norell MA. 1994. Skeletal Morphology of Mononykus olecranus (Theropoda: Avialae) from the Late Cretaceous of Mongolia. Amer Mus Novitates 3105: 1-29.

Perle A, Norell M And Clark J. 1999. A new maniraptoran theropod - Achillobator giganticus (Dromaeosauridae) - from the Upper Cretaceous of Burkhant, Mongolia. Contrib Dept Geol Natl Univ Mongolia 101: 1-105.

Poblete F And Calvo JO. 2003. Upper Turonian Dromaeosaurid teeth from Futalognko quarry, Barreales Lake, Neuquén, Patagonia, Argentina. Ameghiniana 40(Supl): 66R.

Pol D And Apesteguía S. 2005. New Araripesuchus remains from the Early Late Cretaceous (Cenomanian-Turonian) of Patagonia. Amer Mus Novitates 3490: 1-38.

Porfiri JD AND CALVO JO. 2007. La validez taxonómica de Neuquenraptor argentinus (Theropoda, Dromaeosauridae) y la monofilia del nodo Unenlagiinae. Ameghiniana 44 (Supl): 34R.

Porfiri JD, CALVo JO, dos SANTOS D AND JUÁREZ VALIERI RD. 2007. New record of Neuquenraptor (Theropoda, Dromaeosauridae) from the Late Cretaceous of Patagonia. Ameghiniana 44(Supl): 34R.

Powell JE. 1987. Hallazgo de un dinosaurio hadrosáurido (Ornithischia, Ornithopoda) en la Formación Allen (Cretácico Superior) de Salitral Moreno, Provincia de Río Negro, Argentina. X Congreso Geológico Argentino, Actas 3: $149-152$.

RAuhut OWM. 2003. The interrelationships and evolution of basal theropods dinosaurs. The Palaeont Assoc, Special Papers in Paleontology 69: 1-214.
RUSSEL DA. 1969. A new specimen of Stenonychosaurus from the Oldman Formation (Cretaceous) of Alberta. Can J Earth Sci 6: 595-612.

SAlgado L AND AzPilicueta C. 2000. Un nuevo saltasaurino (Sauropoda, Titanosauridae) de la Provincia de Río Negro (Formación Allen, Cretácico Superior), Patagonia, Argentina. Ameghiniana 37: 259-264.

Salgado L And Calvo JO. 1999. Nuevos restos de Saltasaurinae (Sauropoda-Titanosauridae) en el Cretácico Superior de Río Negro. Ameghiniana 36(Supl): 53R.

SAlgado L AND CoRIA RA. 1993. El género Aeolosaurus (Sauropoda, Titanosauridae) en la Formación Allen (Campaniano-Maastrichtiano) de la Provincia de Río Negro, Argentina. Ameghiniana 30: 119-128.

SAlgado L AND CORIA RA. 1996. First evidence of an ankylosaur (Dinosauria, Ornitischia) in South America. Ameghiniana 33: 367-371.

SAnkey JT, Brinkman DB, Guenther M And Currie PJ. 2002. Small theropod and bird teeth from the Late Cretaceous (Late Campanian) Judith River Group, Alberta. J Paleont 76: 751-763.

SENTER P. 2006. Comparison of forelimb function between Deinonychus and Bambiraptor (Theropoda: Dromaeosauridae). J Vert Paleont 26: 897-906.

SENTER P. 2007. A method for distinguishing dromaeosaurid manual unguals from pedal "sickle claws". Bull Gunma Mus Nat Hist 11: 1-6.

SuES H-D. 1977. The skull of Velociraptor mongoliensis, a small Cretaceous theropod dinosaur from Mongolia. Paläont Z 51: 173-184.

SuES H-D. 1978. A new small theropod dinosaur from the Judith River Formation (Campanian) of Alberta Canada. Zool J Linnean Soc 62: 381-400.

Turner AH, Pol D, Clark JA, ERickson GM AND Norell MA. 2007. A basal dromaeosaurid and size evolution preceding avian flight. Science 317: 1378-1381.

VARRICHIO DJ. 1997. Troodontidae. In: CURRIE PJ AND PADIAN K (Eds), Encyclopedia of dinosaurs, San Diego: Academic Press, p. 749-754.

Wellnhofer P. 1974. Das fünfte skelettexemplar von $A r$ chaeopteryx. Palaeontographica Abt A 147: 169-216.

Wellnhofer P. 1992. A new specimen of Archaeopteryx from the Solnhofen limestone. In: CAMPBELL JR. KE (Ed), Papers in avian paleontology honoring Pierce Brodkorb. Nat Hist Mus Los Angeles County Sci Series 36: $3-24$.

Wellnhofer P. 1993. Das siebte exemplar von Archaeopteryx litographica aus den Solnhofener Schichten. Archaeopteryx 11: 1-47. 
WITMER LM. 1997. The evolution of the antorbital cavity of archosaurs: a study in soft-tissue reconstruction in the fossil record with an analysis of the function of pneumaticity. J Vert Paleont 17(Suppl1): 1-73.

XU X AND Norell MA. 2004. A new troodontid dinosaur from China with avian-like sleeping posture. Nature 431: 838-841.

Xu X, Norell M, Wang X-L, Makovicky PJ And Wu X. 2002. A basal troodontid from the Early Cretaceous of China. Nature 415: 780-784.

XU X And WAng X. 2004. A new troodontid (Theropoda: Troodontidae) from the Lower Cretaceous Yixian Formation of Western Liaoning, China. Acta Geol Sinica 78: 22-26.

Xu X And Wang X-L. 2000. Troodontid-like pes in the dromaeosaurid Sinornithosaurus. Paleont Soc Korea Special Publication 4: 179-188.

Xu X, Wang X-L And Wu X-C. 1999. A dromaeosaurid dinosaur with a filamentous integument from the Yixian Formation of China. Nature 401: 262-266.

XU X AND Wu X-C. 2001. Cranial morphology of Sinornithosaurus millenii Xu et al. 1999 (Dinosauria: Theropoda: Dromaeosauridae) from the Yixian Formation of Liaoning, China. Can J Earth Sci 38: 1739-1752.
Xu X, Zhao Q, Norell M, Sullivan C, Hone D, ERICKSON G, WANG X, HAN F AND GUO Y. 2009. A new feathered maniraptoran dinosaur fossil that fills a morphological gap in avian origin. Chinese Sci Bull 54: 430-435.

Xu X, Zhou Z And WAng X. 2000. The smallest known non-avian theropod dinosaur. Nature 408: 705-708.

Xu X, Zhou Z, Wang X, Kuang X, Zhang F and Du X. 2003. Four winged dinosaurs from China. Nature 421: 335-340.

Zheng X, Xu X, You H, Zhao Q And Dong Z. 2010. A short-armed dromaeosaurid from the Jehol Group of China with implications for early dromaeosaurid evolution. Proc Roy Soc B 277: 211-217.

ZhOU Z AND Hou L. 2002. The discovery and study of mesozoic birds in China. In: CHIAPPE LM AND WITMER LM (Eds), Mesozoic birds: Above the head of dinosaurs, Berkeley, Los Angeles and London: University of California Press, p. 160-183.

ZhOU Z AND Zhang F. 2002. A long-tailed, seed-eating bird from the Early Cretaceous of China. Nature 418: 405-409.

ZHOU Z AND ZHANG F. 2003. Jeholornis compared to Archaeopteryx, with a new understanding of the earliest avian evolution. Naturwissenschaften 90: 220-225. 